\title{
Moralidade e Socialização: Estudos Empíricos sobre Práticas Maternas de Controle Social e o Julgamento Moral
}

\author{
Cleonice Camino $^{1}$ \\ Universidade Federal de Pernambuco \\ Leoncio Camino \\ Universidade Federal da Paraíba \\ RaquelMoraes \\ Universidade Estadual da Paraíba
}

\begin{abstract}
Resumo
Este estudo teve 3 objetivos. O primeiro foi investigar as práticas de controle social utilizadas pelas mães para evitar comportamentos indesejados de seus filhos. O segundo foi verificar a relação entre as práticas maternas de controle social e o julgamento moral dos filhos. Por fim, o terceiro foi validar o questionário de práticas maternas de controle respondido pelas mães. Para tanto, foram realizadas 3 pesquisas: duas de campo - em que foram avaliadas as técnicas de controle preventivo utilizadas pelas mães e a sua relação com o julgamento moral dos filhos - e uma de campo e laboratório - em que foi verificada a validade do questionário. Participaram do primeiro estudo 110 díades de mães-filhos; do segundo, 222 díades; do terceiro, 72 mães, das quais 22 foram observadas com seus filhos em situação de laboratório. A idade das crianças variou de 5 a 11 anos. As mães responderam a um questionário sobre técnicas de controle e as crianças a dilemas morais. As respostas das mães mostraram a existência de dois fatores, que foram considerados como controle interno e externo. O controle interno, de uma forma geral, associou-se a um nível mais elevado de desenvolvimento moral do que o controle externo. Os comportamentos das mães no laboratório foram consistentes com suas respostas aos questionários.

Palavras-chave: Práticas maternas de controle social; julgamento moral; validação de instrumento.
\end{abstract}

\section{Morality and Socialization: Empirical Studies on Maternal Practices of Social Control and the Moral Judgment}

\begin{abstract}
This study had 3 goals. The first aim was to explore maternal practices of social control used by mothers to avoid undesirable behavior of their children. The second goal was to investigate the relationship between maternal practices of social control and children's moral judgement. The last goal was to validate mothers' answers on maternal practices of social control. In order to attain these goals, field and laboratory studies were conducted: two field studies evaluated the preventive control techniques used by mothers and the relationship of these techniques with the moral judgement of their children. In a third study (field and laboratory studies) the questionnaire answeredd by mothers was validated. The first study had 110 mother-child dyads. The second study had 222 mother-child dyads. The third study had 72 mother-child dyads, 22 of which were observed with their children during a laboratory situation. The children's age varied from 5 to 11 years old. The mothers' answers showed the presence of two factors considered as inner and external controls. The inner control was associated to a higher level of moral judgement than the external. Mothers' behavior in the laboratory showed consistency with their answered in the questionnaire. Keywords: Maternal practices of social control; moral judgement; questionnaire validity.
\end{abstract}

Nestas duas últimas décadas, o Brasil e a América Latina estão passando por um conjunto de crises dramáticas. Entre estas, as crises política e econômica parecem sobressair com muita evidência. Mas o observador atento notará que, entrelaçada a essas, vem se desenvolvendo uma forte crise de valores morais. Os numerosos processos de cassação política por corrupção nos mais altos níveis dos três poderes, nos Estados latino-americanos, são uma prova da crise moral

\footnotetext{
${ }^{1}$ Endereço para correspondência: Rua da Aurora, 201/908, 58043 270, Miramar, João Pessoa, PB. E-mail: cleocamino@yahoo.com.br
}

nas instituições políticas. O vale-tudo na luta pelos lucros como recentemente tem sido demonstrado no Brasil através das altas nos preços, maquiadas pela redução no conteúdo de vários produtos domésticos vendidos nos supermercados, e através dos ganhos exorbitantes da indústria farmacêutica - mostra a decadência moral do setor produtivo privado.

Essa crise institucional vem contaminar, de alguma forma, os cidadãos. A crença no "rouba mas faz" nas campanhas eleitorais, a prática institucionalizada da "Lei de Gerson" aquela de levar vantagem em tudo - a resistência à aplicação de uma regulamentação mais sensata ao trânsito, são alguns 
exemplos que demonstram essa ausência de valores morais e sociais de que padece a sociedade brasileira.

Embora a moral forme "uma estrutura de princípios, idéias e preceitos muito complexa, e incorpora todos os elementos de pensamento, comportamento e sentimento" (Rawls, 1971/1981, p. 340), ela pode ser interpretada como "um conjunto de normas aceitas, livre e conscientemente, que regulam o comportamento individual e social dos homens" (Vasquez, 1969/1983, p. 49). Entendendo a moral nesses termos, acredita-se que a crise moral que atinge a sociedade brasileira pode ser vista como fazendo parte de uma crise moral mais ampla que pode ser debitada, em grande parte, às formas que o capitalismo toma atualmente, o qual, segundo Apel (1992), gerou progressos técnicos e científicos sem ter gerado uma ética compatível com esses progressos, uma ética baseada na cooperação, tendo como tônica a responsabilidade solidária. Ao contrário, segundo Habermas (1973/1978), o capitalismo neo-liberal propicia a manutenção de uma ética voltada para os valores especificamente burgueses do individualismo possessivo e do utilitarismo benthianiano. Além disso, para Habermas, o capitalismo neo-liberal provoca uma crise de motivação que se revela através de: atitudes individualistas e opiniões despolitizadas na vida pública; adesão a valores dirigidos ao lazer e ao consumo na vida familiar; e adoção de valores compatíveis com a concorrência pelo status social na vida profissional. É neste sentido que Camino, Da Silva, Machado e Pereira (2001) afirmam que a mentalidade pós-moderna inclui tanto aspirações universais e globalizantes como aspirações setoriais (nacionalistas) que o espírito de concorrência e a meritocracia capitalista inculcam. Por isso, na mentalidade pós-moderna, coabitam aspirações moralistas de fraternidade e de igualdade e preocupações realistas de justiça concreta, num mundo visto, essencialmente, como competitivo.

Relacionados ao sistema capitalista, outros fatores históricos, culturais, sociais e políticos - também têm contribuído para a profunda crise moral brasileira. Mas sejam quais forem estes fatores, não cabe a menor dúvida de que diversos mecanismos de socialização estão em jogo na explicação da profundidade e extensão desta crise, fato que justificaria uma análise psicossocial do modo como é transmitida a moral. Nesse sentido, em que consiste o processo de socialização?

$\mathrm{Na}$ psicologia americana, o processo de socialização tem sido estudado à luz de diferentes abordagens teóricas, como o behaviorismo e a psicanálise, mas com uma única perspectiva: a de entender como os indivíduos adquirem hábitos, crenças e valores culturalmente compartilhados e como incorporam as regras sociais (Maccoby, 1994; Zigler \& Child, 1969). O simples enunciado de algumas definições de socialização no campo da Psicologia ${ }^{2}$ colocará em evidência a concepção funcionalista implícita nesta perspectiva.

Esperando pela criança, existe uma sociedade que possui uma cultura. A criança é colocada no meio de uma forma organizada de viver, possuindo certas possibilidades para processar informação e desenvolvendo motivos que permitem que esta forma organizada de viver possa influenciá-la. (Brown, 1965, p. 193)

A socialização refere-se à adoção e internalização, pelo indivíduo, de valores, crenças e maneiras de perceber o mundo que são compartilhadas pelo grupo. Quando a internalização é efetiva, o indivíduo termina por desejar comportar-se da maneira que os outros desejam e esperam que o faça, enquanto membro responsável do grupo. (Jones \& Gerard, 1967, p. 76)

A socialização é o processo pelo qual o comportamento de uma pessoa é modificado a fim de se conformar com as expectativas dos membros do grupo ao qual ela pertence. (Secord \& Backman, 1964, p. 462)

Essas definições de socialização, representativas da perspectiva adotada nos Estados Unidos, pressupõem um forte determinismo social, onde, por um lado, o social é concebido como algo externo, estático e em certo sentido abstrato e, por outro lado, o sujeito, isolado em sua individualidade, é visto como um aprendiz mais ou menos passivo dos elementos sociais apresentados a ele (Camino, 1996).

Já na Europa, Piaget (1975), embora mantendo o funcionalismo darwinista subjacente a psicologia americana, acentua os aspectos dinâmicos do comportamento do sujeito. Ele afirma que o conhecimento se desenvolve através de uma construção ativa do organismo, quando opera sobre o meio ambiente, construção composta inicialmente de estruturas - ou estágios - simples que evoluem, gradualmente, para estruturas complexas, cada vez mais abstratas, em busca de um melhor equilíbrio. Os estágios indicam a forma adaptativa e dialética com que a mente adequa-se ao meio ambiente em cada momento da evolução do indivíduo. Por sua vez, as formas de interação da criança com o seu meio social retratam as características próprias de seu estágio evolutivo.

$\mathrm{Na}$ perspectiva clássica, três instâncias sociais seriam responsáveis pela adaptação do sujeito à sociedade: a

\footnotetext{
${ }^{2}$ A comparação entre as definições da socialização dos diversos campos do saber como a antropologia, a psicanálise, a psicologia social, a psicologia construtivista, a genética, etc (Zigler \& Child, 1969) permite constatar que, embora se diferenciem entre elas, no que concerne à natureza passiva ou ativa da participação da criança, concordam quanto ao papel externo e determinístico do social
} 
família, a escola e os meios de comunicação. Mas cabe também a Piaget (1932), ao analisar o desenvolvimento moral, colocar em relevo a importância dos pares no processo de socialização. Na realidade, para Piaget, a relação de obediência da criança com o adulto favorece o desenvolvimento de uma moral heterônoma. É somente através da cooperação entre pares que a criança torna-se capaz de uma moral autônoma. Isto porque, por mais que $\mathrm{o}$ adulto procure compreender o ponto de vista da criança e procure estabelecer uma comunicação de igual para igual, as relações entre eles permanecem hierarquizadas, propiciando apenas o respeito unilateral da criança para com $\mathrm{o}$ adulto. As relações entre crianças, ao contrário, propiciam a descentração - cada um torna-se capaz de se colocar no lugar do outro - e, juntamente com a descentração, surgem o sentimento de reciprocidade e o respeito mútuo, elementos indispensáveis para uma moral autônoma.

Embora, classicamente, o grupo tenha sido o objetivo visado no processo de socialização, estudos recentes mostram o papel relevante que o próprio grupo desempenha como agente de socialização (Tajfel, 1981). Para entender isso, devese ter em conta que as interações entre os níveis psicológico e sociológico são processos de "mão dupla". Numa direção, os processos subjetivos são influenciados pelas formas concretas que uma formação social adota; enquanto que, na direção oposta, as formações sociais são construídas, dinamicamente, pelo conjunto de representações e ações dos indivíduos que as constituem.

Assim, no processo de socialização, crianças e adolescentes começariam a reconhecer seus interesses a partir de sua inserção ativa nos diversos grupos da sociedade. Esse aspecto da socialização se apoiaria, principalmente, nos processos de constituição da identidade social. De fato, os grupos construiriam suas identidades nas relações inter-grupais e os sujeitos se "socializariam" neste processo (Camino, 1996).

$\mathrm{Na}$ realidade, é na interação com os outros grupos que um grupo constrói, conjuntamente com os sujeitos que a ele pertencem, os valores e normas que formam a identidade social desses sujeitos. Neste sentido, os jovens não só se adaptariam a grupos já existentes, mas participariam de grupos onde ativamente construiriam suas normas e suas identidades sociais. Portanto, não são as pessoas que se socializam individualmente, mas são os grupos que se socializam na dinâmica das relações que mantêm com os outros grupos (Camino, 1996).

Entretanto, deve-se considerar que os grupos não se desenvolvem num vácuo social, mas no interior de formações sociais, econômicas e de formações políticas com ideologias específicas. As características das formações sociais influenciam as relações intergrupais, mas também são conseqüências dessas relações. É neste contexto interativo que deve ser analisada a influência dos meios de comunicação na socialização da moralidade.

Em um estudo sobre valores transmitidos pelos meios de comunicação, Camino e Cavalcanti (1998) analisaram, seguindo a tipologia de Kohlberg $(1976,1984)$, algumas novelas da Rede Globo e observaram que os valores transmitidos com maior freqüência eram relativos a uma moral heterônoma ou constituíam seus reforçadores: o domínio e o poder sobre os outros às custas de agressões e chantagens, a justiça expiatória, a justiça retaliativa, o oportunismo (usar o outro para a consecução de benefícios pessoais), a desonestidade e a não assunção das conseqüências dos seus próprios atos.

Já Camino e colaboradores (1994) observaram que tanto os personagens identificados como muito simpáticos como os pouco simpáticos transmitem valores de moral heterônoma, porém os muito simpáticos transmitem mais freqüentemente esses valores, embora transmitam, também, valores referentes ao bem-estar e à proteção do outro. Em um outro estudo, Camino, Cavalcanti e Rique (1992), estudando adolescentes que se situam no nível convencional da tipologia kohlbergiana, observaram que: quanto maior o nível de empatia para com os personagens considerados pouco atrativos, maior o nível de adesão aos valores heterônomos transmitidos por esses personagens; e o nível de adesão aos valores morais heterônomos é significativamente mais elevado em relação aos personagens da telenovela do que em relação a personagens fictícios do questionário. Assim, esse estudo mostra que a empatia dos telespectadores por personagens de telenovelas pode diminuir sua capacidade crítica.

As formas como se socializam os indivíduos são, portanto, múltiplas e bastante complexas. Certamente, fazse necessário não só analisar o papel dos diversos agentes de socialização no desenvolvimento dos princípios morais, como recolocar estas influências nos contextos sociais, econômicos e políticos nos quais elas se efetuam. Mas, apesar desta complexidade, a Psicologia, pela sua própria tradição, centrou-se, até meados do século XX, na análise do papel das relações familiares no desenvolvimento dos princípios morais, tendo, apenas nas últimas décadas, se deslocado, sob a influência do construtivismo, para o contexto escolar, a fim de estudar a influência dos pares no processo de socialização (Walker, 1999). A centralização na família, entretanto, tem sua razão de ser, pois, de fato, por mais que as normas e os processos de socialização variem segundo os diversos contextos sociais, econômicos e políticos, o papel dos pais continua sendo o de avaliar se os comportamentos dos filhos são ou não adequados a essas normas, uma vez que a sua responsabilidade sobre os 
comportamentos dos filhos é uma constante que transcende a diversidade das normas culturais (Darling \& Steinberg, 1993).

Além disso, deve-se também ter em conta que a conduta dos pais não é só determinada pelo contexto sócio-cultural em que ocorre, mas que ela também é afetada pelo comportamento dos próprios filhos. Esta influência tem sido observada já no aleitamento, quando mãe e criança estabelecem, em intercâmbio mútuo, o ritmo de alimentação (Kaye, 1982). No que concerne especificamente às técnicas de controle, Schaffer (1984) tem observado que o padrão de interação vocal e de gestos entre a mãe e o bebê servirá posteriormente de base para o ritmo do diálogo nas futuras ocasiões de controle. Por sua vez, Chapman (1979) tem mostrado como disposições concretas das crianças delimitam a intervenção parental. Assim, este autor constata que, em situações em que os filhos estão muito desatentos, ordens dadas por suas mães de forma simples e clara são mais eficazes do que o diálogo para conseguir que eles se comportem corretamente.

Mas, uma determinada situação, em um contexto específico, não permite caracterizar a relação entre pais e filhos. É necessário que se estabeleçam certas relações constantes entre as formas como os pais atuam em relação ao comportamento dos filhos e as diferentes situações do cotidiano, para caracterizar um estilo de atuação chamado de estilo de socialização. De acordo com Musitu e García (2001, p. 9), "os estilos de socialização parental se definem pela persistência de certos padrões de atuação e pelas conseqüências que esses padrões têm para a própria relação pais-filhos".

De fato, os estilos de socialização seriam caracterizados por um conjunto de técnicas e formas de atuação que abrangem desde atitudes de aceitação até atitudes de controle dos comportamentos indesejados e imposição de limites aos filhos. Essas últimas se constituem no que a literatura denomina de controle parental. Neste campo de estudo, destacase, como uma das contribuições mais importantes, os trabalhos de Hoffman sobre a socialização (1960, 1963a, 1963b, 1970, 1975). Hoffman (1983, 1994) distingue três técnicas de socialização utilizadas pelos pais: a indução, a retirada de afeto e a afirmação de poder.

A indução consiste no emprego, pelos agentes de socialização, de explicações que levam a criança a se convencer de que seu comportamento é inadequado. Esta técnica chama a atenção da criança para as conseqüências naturais de sua ação, voltadas seja para ela mesma, seja para o outro (Hoffman \& Saltzstein, 1967). Já a retirada de afeto consiste em mostrar à criança que seu comportamento teve ou pode ter por conseqüência a ruptura de um elo afetivo entre ela e o adulto. Finalmente, a afirmação de poder é constituída pelo emprego de coerção externa, ou de força física, para impedir ou punir uma falta cometida. Como exemplo dessa técnica, esses autores citam todas as formas de punição real, salvo a retirada de afeto.

Analisando as técnicas enquanto processo de informação, Hoffman (1963a, 1975, 1983, 1994) diz que o efeito delas sobre a socialização depende de dois componentes: grau de pressão e conteúdo. O grau de pressão de uma técnica é a capacidade que ela tem de provocar uma ativação afetiva - ansiedade - devido ao bloqueio de um comportamento motivado. O conteúdo é o aspecto qualitativo da técnica, é a informação que a técnica pode fornecer. Assim, no que se refere ao grau, a afirmação de poder provocaria o nível mais elevado de ansiedade na criança, a retirada de afeto um nível médio e a indução um nível baixo dessa ansiedade. No que se refere ao conteúdo, a afirmação de poder imposição, ameaça, chantagem - e a retirada de afeto expressões de raiva e distanciamento - mostram formas de se relacionar com as pessoas que não proporcionam conteúdos para o aparecimento de uma estrutura moral, enquanto que a indução, ao mostrar as possíveis conseqüências das ações para os outros, favorece o aparecimento de uma estrutura de controle moral.

Tentando aprofundar os mecanismos pelos quais atuam as diversas técnicas, Aronfreed (1968) distingue duas técnicas, uma orientada para o amor e outra para a aplicação de estímulos aversivos. Constam da primeira técnica categorias prototípicas, como a retirada de afeto e a explicação. A segunda tem como categoria prototípica a punição física, que inclui também agressões verbais e injúrias. Essas duas técnicas podem ser vistas como envolvendo, respectivamente, dois padrões de aprendizagem: a indução e a sensibilização. Esses padrões, por sua vez, podem ser vistos como sendo responsáveis pela orientação interna ou externa que a criança adquire, no controle do seu comportamento aberto: a indução, por não depender de contingências externas, produziria na criança mais do que a sensibilização - que depende de contingências externas -, guias internalizados de ansiedade e recursos instrumentais que seriam utilizados para redução da ansiedade em face de comportamentos de transgressão. Note-se porém que, posteriormente, Aronfreed (1976) considera que a retirada de afeto pode fazer parte da punição, desde que esta seja definida de uma forma mais ampla incluindo, por exemplo, a rejeição e a desaprovação.

No que concerne aos estilos ou combinações das diferentes técnicas, Baumrind (1968, 1971, 1991, 1996) propõe um modelo que integra as diferentes formas de cuidar da criança. Nesse modelo, a autora rejeita a simples oposição entre o autoritário e o permissivo considerando que os papéis da punição e da coerção dependem do 
contexto sócio-cultural em que essas técnicas são utilizadas, bem como da conjugação delas com exigências parentais (confrontação, disciplina constante e contingente, orientação) e das técnicas afetivas (uso da empatia, reciprocidade e comunicação clara e centrada na pessoa). Tendo como base uma distribuição de crianças em três grupos, classificados a partir das características sócio-emocionais dessas crianças, Baumrind $(1968,1971)$ identificou, inicialmente, três estilos educativos usados pelos pais dessas crianças:

- Pais diretivos - controladores e exigentes, mas também calorosos, empáticos, comunicativos e compreensivos com os seus filhos, que usam tanto a indução como a punição;

- Pais autoritários - distantes, pouco empáticos, controladores e, sobretudo, punitivos com os seus filhos;

- Pais permissivos - não controladores, não exigentes, relativamente calorosos, e empáticos, que se comportam de forma não punitiva.

Baumrind (1971) verificou, em uma pesquisa realizada com 146 crianças e suas famílias, que, nas meninas, o controle utilizado pelos pais diretivos associava-se positivamente com todos os índices de responsabilidade social. Já o controle parental autoritário associava-se negativamente aos índices de responsabilidade social. Quanto ao controle permissivo, quando associado a um certo grau de rejeição paterna, parecia facilitar tanto a expressão de forças autônomas de natureza construtiva como de natureza socialmente destrutiva.

Posteriormente, Baumrind (1991, 1996) acrescentou ao modelo anterior os pais não engajados - aqueles que não são exigentes, não são empáticos e não demonstram interesse pelos seus filhos.

Partindo dos pressupostos teóricos já apresentados, pode-se indagar: como as diversas técnicas ou os diversos estilos de socialização parental influenciam o desenvolvimento da moralidade? Para Hoffman $(1983,1994)$ e Aronfreed (1968), a indução favoreceria uma moral autônoma, enquanto a afirmação de poder e a retirada de afeto favoreceriam uma moral heterônoma. Já para Piaget (1932), a moral autônoma poderia ser adquirida nas relações com os pares. Baumrind, por sua vez, considerando a influência da indução e da afetividade nos estilos, afirma que os pais diretivos facilitariam mais a internalização dos valores morais do que os permissivos, estes mais do que os autoritários e estes mais do que os não engajados.

Como já foi observado, os trabalhos efetuados sobre a influência das técnicas de controle parental no comportamento das crianças têm sido realizados, principalmente, nos Estados Unidos. Mas será que em outras culturas as técnicas de controle do comportamento das crianças produzem os mesmos resultados que os observados nos Estados Unidos? A fim de responder a esta pergunta, decidiu-se elaborar um projeto de estudos sobre o tema, focalizando a figura materna como agente de socialização. No presente escrito, será apresentado, inicialmente, um estudo exploratório em que se testaram os instrumentos e levantaram-se os primeiros dados sobre as relações existentes, na Paraíba, entre o controle materno e o desenvolvimento do julgamento moral. Em um segundo momento, será apresentado um estudo mais amplo, que procurou confirmar os resultados obtidos no primeiro estudo. Finalmente, mostrar-se-á um estudo que pretendeu validar experimentalmente o conteúdo das escalas utilizadas nos estudos anteriores e observar diretamente a relação entre técnicas de controle e julgamento moral.

\section{$1^{\circ}$ Estudo, de Caráter Exploratório, sobre as Relações entre o Controle Materno e o Desenvolvimento do Julgamento Moral}

Em seus estudos, Hoffman $(1983,1994)$ considerou a existência de três técnicas de controle: a ameaça de punição real, a ameaça de retirada de afeto e a explicação das conseqüências da ação proibida. Mas, na realidade do Nordeste, essa classificação parece limitada, na medida em que não contempla formas de controle muito usadas nesse meio social. Uma primeira constatação é que, de fato, as mães no Nordeste, como na maioria das culturas, utilizam, como forma de controlar o comportamento da criança, a promessa de uma gratificação ou reforço positivo: "Se ficas bem comportado, ganharás um chocolate". Mas também observa-se, tanto no Nordeste como em outras culturas de predominância rural, ameaças de punição que apelam para um mundo mítico ou sobrenatural: "Se não vais dormir, o bicho-papão vai te pegar". Com vistas a adaptar o presente estudo à realidade nordestina, decidiu-se incluir, neste primeiro trabalho exploratório, tanto a promessa de reforço positivo como a ameaça de punição sobrenatural ${ }^{3}$.

Mas a inclusão dessas duas técnicas responde também a questionamentos teóricos. Assim, a inclusão do reforço encontra-se justificada pelo fato de ter sido verificado que os efeitos desta técnica no controle do comportamento das crianças - amplamente pesquisados em laboratório nas décadas de 1960 e 1970 - diferem dos da punição (Aronfreed, 1968; Bandura, 1977; Parke, 1977). Deve-se salientar que, nessas pesquisas, o reforço aparece associado a comportamentos, geralmente pró-sociais, e não a

\footnotetext{
${ }^{3}$ Usando o termo sobrenatural não se está fazendo, necessariamente, referência a reflexões de caráter religioso, embora considere-se que ameaças como "Se falas palavrões, o diabo vai te levar" enquadram-se perfeitamente neste tipo de técnica.
} 
julgamentos de ordem moral. Já a inclusão de uma técnica de ameaça com conteúdos referentes ao sobrenatural permite investigar a hipótese de Piaget (1964) de que o animismo mítico e imanente, característico do pensamento infantil, pode ser reforçado pela educação do adulto.

Em relação a esse primeiro estudo, foram levantadas as seguintes hipóteses:

1) O controle pela explicação das conseqüências naturais negativas dos atos estará relacionado a um melhor desenvolvimento do julgamento moral;

2) As técnicas não explicativas que demonstram o uso do poder por parte do adulto, como a promessa de recompensa, a ameaça de punição real pelos agentes de socialização e a ameaça de punição por entidades sobrenaturais (Deus ou Diabo, ou outros seres mitológicos do folclore do Nordeste do Brasil) - técnica sobrenatural -, estarão relacionadas com um desenvolvimento mais pobre do julgamento moral infantil.

\section{Método}

Decidiu-se verificar, numa situação natural, a relação existente entre a forma como a mãe diz controlar o comportamento da criança e o nível de desenvolvimento do julgamento moral desta. Para isso, foram convidadas as mães de crianças que cursavam o primário em uma escola da rede pública de João Pessoa, para responder a um questionário sobre as técnicas que utilizavam para controlar o comportamento dos filhos.

\section{Participantes}

Foram entrevistadas 110 crianças e suas respectivas mães. As crianças encontravam-se distribuídas em cinco grupos de idade: 7 anos ( 9 meninos e 10 meninas), 8 anos (11 meninos e 11 meninas), 9 anos (10 meninos e 10 meninas), 10 anos (15 meninos e 13 meninas) e 11 anos (11 meninos e 10 meninas). As mães, que aceitaram voluntariamente o convite para participar do estudo, trabalhavam, em sua maioria, como empregadas domésticas e não tinham o primário completo.

\section{Instrumentos}

Para a avaliação do Julgamento Moral das crianças, foram utilizados oito pares de histórias, elaboradas por Camino, Camino e Leyens (1996), a partir das histórias utilizadas por Piaget (1932) no seu estudo sobre o julgamento moral. O escore do julgamento foi obtido através do número de respostas corretas às perguntas sobre qual era o personagem mais errado. $\mathrm{Na}$ avaliação das técnicas de controle, perguntou-se às mães com que freqüência elas empregavam cada uma das quatro técnicas (promessa de recompensa, explicação, ameaça de punição real e ameaça de punição sobrenatural), quando pretendiam controlar o comportamento de seu filho nas seguintes situações: comer, ir dormir, fazer os deveres da escola, lavarse, brigar fisicamente, agredir verbalmente, mentir, dizer palavrões, pegar escondido coisas alheias, brincar com objetos perigosos, fazer jogos sexuais, sair para a rua sem autorização e brincar com objetos de valor. Cada técnica aparecia associada a estes 13 comportamentos. Para cada técnica, as mães deveriam indicar, em uma escala de 5 pontos ( 5 correspondendo a Sempre e 1 a Nunca), a freqüência com que utilizavam a técnica em cada um dos 13 comportamentos. $\mathrm{O}$ instrumento tinha 52 questões.

\section{Procedimento}

As mães foram entrevistadas em duas sessões. Elas responderam ao questionário sobre técnicas de controle em vários grupos de, no máximo, 25 mães, com a ajuda de vários pesquisadores. A leitura de cada item foi feita em voz alta. Em seguida, os pesquisadores verificavam como cada mãe havia marcado a resposta. Por tratar-se de uma pesquisa exploratória, perguntava-se ao grupo de mães, no final da entrevista, sobre o grau de dificuldade e de pertinência do questionário utilizado. As crianças foram entrevistadas individualmente em uma sessão. A ordem de apresentação das histórias foi aleatória.

\section{Resultados}

Analisar-se-ão, inicialmente, as diversas técnicas maternas de controle do comportamento, a fim de ver se essas técnicas se agrupam em torno dos eixos principais previstos por Hoffman. Num segundo momento, serão analisadas as relações existentes entre as técnicas usadas pelas mães e o julgamento moral das crianças.

\section{Técnicas de Controle: Seus Eixos de Organização}

Foi efetuada sobre os escores dos 52 itens do questionário uma Análise dos Componentes Principais (com rotação ortogonal). Os resultados mostram que as 52 questões correspondem a dois fatores principais que explicam $46 \%$ da variância dos dados, conforme Tabela 1 . O primeiro fator, que explica $35 \%$ da variância e possui um coeficiente de fidedignidade $\alpha$ de Crombach de 0,89, é formado por 39 itens do questionário, dos quais 13 itens pertencem à técnica de recompensa, 13 à técnica de punição real e 13 à técnica de punição sobrenatural. O segundo fator, que explica $11 \%$ da variância comum e tem um $\alpha$ de Crombach de 0,89, é formado por 12 dos 13 itens relativos à técnica de explicação. 
Tabela 1

Índices de Saturacão dos dois Fatores Obtidos pela Análise dos Componentes Principais dos Escores do Instrumento de Técnicas de Controle

\begin{tabular}{|c|c|c|c|}
\hline Técnicas & Comportamentos & Fator I & Fator II \\
\hline \multirow{13}{*}{ Recompensa } & Comer & 0,70 & \\
\hline & Ir dormir & 0,55 & \\
\hline & Fazer os deveres da escola & 0,69 & \\
\hline & Lavar-se & 0,69 & \\
\hline & Brigar fisicamente & 0,74 & \\
\hline & Agredir verbalmente & 0,73 & \\
\hline & Mentir & 0,66 & \\
\hline & Dizer palavrões & 0,68 & \\
\hline & Pegar escondido coisas alheias & 0,46 & \\
\hline & Brincar com objetos perigosos & 0,74 & \\
\hline & Fazer jogos sexuais & 0,70 & \\
\hline & Sair para rua sem autorização & 0,73 & \\
\hline & Brincar com objetos de valor & 0,57 & \\
\hline \multirow{13}{*}{ Explicação } & Comer & & 0,47 \\
\hline & Ir dormir & & 0,60 \\
\hline & Fazer os deveres da escola & & \\
\hline & Lavar-se & & 0,70 \\
\hline & Brigar fisicamente & & 0,60 \\
\hline & Agredir verbalmente & & 0,72 \\
\hline & Mentir & & 0,69 \\
\hline & Dizer palavrões & & 0,63 \\
\hline & Pegar escondido coisas alheias & & 0,55 \\
\hline & Brincar com objetos perigosos & & 0,67 \\
\hline & Fazer jogos sexuais & & 0,74 \\
\hline & Sair para rua sem autorização & & 0,70 \\
\hline & Brincar com objetos de valor & & 0,53 \\
\hline \multirow{13}{*}{ Punição real } & Comer & 0,68 & \\
\hline & Ir dormir & 0,74 & \\
\hline & Fazer os deveres da escola & 0,73 & \\
\hline & Lavar-se & 0,66 & \\
\hline & Brigar fisicamente & 0,56 & \\
\hline & Agredir verbalmente & 0,80 & \\
\hline & Mentir & 0,55 & \\
\hline & Dizer palavrões & 0,69 & \\
\hline & Pegar escondido coisas alheias & 0,68 & \\
\hline & Brincar com objetos perigosos & 0,68 & \\
\hline & Brincadeiras Sexuais & 0,68 & \\
\hline & Sair para rua sem autorização & 0,56 & \\
\hline & Brincar com objetos de valor & 0,64 & \\
\hline \multirow{13}{*}{ Punição sobrenatural } & Comer & 0,75 & \\
\hline & Ir dormir & 0,76 & \\
\hline & Fazer os deveres da escola & 0,77 & \\
\hline & Lavar-se & 0,68 & \\
\hline & Brigar fisicamente & 0,76 & \\
\hline & Agredir verbalmente & 0,69 & \\
\hline & Mentir & 0,64 & \\
\hline & Dizer palavrões & 0,77 & \\
\hline & Pegar escondido coisas alheias & 0,58 & \\
\hline & Brincar com objetos perigosos & 0,78 & \\
\hline & Brincadeiras sexuais & 0,65 & \\
\hline & Sair para rua sem autorização & 0,73 & \\
\hline & Brincar com objetos de valor & 0,68 & \\
\hline \multirow[t]{3}{*}{ Estatísticas } & Eigenvalue & 18,73 & 6,50 \\
\hline & $\%$ de variabilidade explicada & $35 \%$ & $11 \%$ \\
\hline & Coeficiente $\alpha$ de Crombach & 0,89 & 0,91 \\
\hline
\end{tabular}


Com efeito, as três técnicas de controle - ameaça de punição real, punição sobrenatural e promessa de recompensa - formam uma única atitude, onde o controle é posto sobre as conseqüências negativas ou positivas que não estão diretamente ligadas à ação controlada. $\mathrm{O}$ que caracteriza o primeiro fator é, precisamente, o acento sobre as conseqüências não intrínsecas à ação, mas externas a ela. Por esta razão, o fator foi denominado de Controle Externo. O segundo fator, ao contrário, traduz uma atitude em que o controle baseia-se na ênfase que é dada às conseqüências intrínsecas da ação e, por isso, foi denominado de Controle Interno. Análises internas mostraram que nem a idade nem o gênero das crianças afetaram significativamente a freqüência com que as mães utilizaram as duas técnicas de controle.

\section{Técnicas de Controle e Desenvolvimento Moral}

Com respeito à relação existente entre técnicas de controle e desenvolvimento moral, uma maneira de abordar a questão seria correlacionar os escores obtidos pelas crianças nos testes de moralidade com os escores dados pelas mães às duas técnicas principais. Mas isto pressuporia a existência de uma relação linear entre os dois tipos de controle e o julgamento moral, suposição esta que se mostrou inadequada, após uma primeira análise descritiva dos dados. ao julgamento moral, foram considerados, separadamente, os escores para as histórias que versavam sobre situações de agressão e os escores das que versavam sobre situações de roubo.

A Análise de Variância dos escores de julgamento moral (Tabela 2) mostra um efeito significativo para o controle externo $(F(2,87)=4,175 ; p<0,025)$ e uma interação significativa entre os dois controles $(F(4,87)=2,48 ; p<0,05)$. A variável tipo de ação também interage com o controle interno $(F(2,87)=5,076 ; p<0,01)$ e com os dois controles $(F(4,87)=7,288 ; p<0,001)$.

Constata-se que os escores do julgamento moral das crianças submetidas a um baixo nível de controle externo $(m=7,2)$ são significativamente superiores aos resultados das crianças submetidas aos níveis médio $(m=6,3)$ e alto $(m=6,3)$ de controle externo. Observa-se, também, como indica a interação significativa, que o efeito do controle externo é função do controle interno. Assim, os escores mais altos de julgamento moral encontram-se nas crianças submetidas a um alto controle interno e a um baixo controle externo ( $m=7,9$ no caso do roubo e $m=7,5$ no caso da agressão) que será denominado aqui de estilo indutivo, enquanto que os escores mais baixos encontram-se em crianças submetidas, simultaneamente, a um alto nível de controle externo e interno ( $m=5,3$ no caso do roubo e $m=5,9$ no

Tabela 2

Médias dos Escores Obtidos no Teste de Julgamento Moral em Funcão dos Tipos de Histórias e dos Niveis de Controle Externo e Interno

\begin{tabular}{ccccc}
\hline \multirow{2}{*}{ Tipo de História } & Controle interno & Baixo & Médio & Alto \\
\cline { 3 - 5 } & Baixo & $7,1 \mathrm{abc}$ & $6,0 \mathrm{defg}$ & $6,9 \mathrm{bcd}$ \\
\multirow{2}{*}{ Agressão } & Médio & $6,8 \mathrm{bcd}$ & $6,0 \mathrm{defg}$ & $6,7 \mathrm{bcde}$ \\
& Alto & $7,5 \mathrm{ab}$ & $6,7 \mathrm{bcde}$ & $5,9 \mathrm{efg}$ \\
& & & & \\
& Baixo & $7,4 \mathrm{ab}$ & $5,6 \mathrm{fg}$ & $5,5 \mathrm{fg}$ \\
Roubo & Médio & $6,3 \mathrm{cdef}$ & $7,3 \mathrm{ab}$ & $7,3 \mathrm{ab}$ \\
& Alto & $7,9 \mathrm{a}$ & $6,2 \mathrm{cdef}$ & $5,3 \mathrm{~g}$ \\
\hline \multirow{2}{*}{ Total controle externo } & & $7,2_{\mathrm{A}}$ & $6,3 \mathrm{~B}$ & $6,3 \mathrm{~B}$ \\
\hline
\end{tabular}

Decidiu-se, pois, efetuar uma Análise de Variância dos escores de julgamento moral, dividindo a amostra das mães em função da freqüência com que utilizavam cada técnica. Assim, para cada tipo de controle, foram estabelecidos três níveis: um de baixa freqüência (abaixo do percentil 33,3), um de freqüência média (entre os percentis 33,4 e 66,6) e um de alta freqüência (acima do percentil 66,6). A combinação dos diferentes níveis dos dois tipos de controle resultou em nove condições diferentes. No que concerne caso da agressão) - que será denominado aqui de estilo restritivo e que corresponderia, parcialmente, ao estilo diretivo de Baumrind $(1968,1971)$. Desta forma, nos casos extremos de controle interno (alto e baixo), o controle externo alto afeta o julgamento moral no sentido que se esperava, isto é, retarda significativamente o desenvolvimento do julgamento moral. De fato, estes efeitos e interações tendem a ser algo mais acentuados, mais nítidos nas respostas às histórias sobre roubo. Nas histórias de agressão, nos níveis 
moderado e baixo de controle interno, o controle externo não parece ter um efeito tão negativo. Nesta situação, quando o controle interno é baixo, parece que o controle externo permite às crianças obter, relativamente, um bom julgamento moral. Pelo contrário, nas histórias sobre roubo nos níveis alto e baixo de controle interno o controle externo é negativo.

Já as crianças submetidas a baixos níveis de controle externo e interno - que será denominado aqui de controle liberal e que corresponderia, parcialmente, ao estilo permissivo da tipologia de Baumrind - apresentam escores semelhantes aos das crianças submetidas a um alto controle interno e baixo controle externo.

\section{Discussão}

O estudo mostra claramente a existência de dois fatores subjacentes às diversas técnicas. Esses dois fatores, que foram denominados de controle externo e controle interno, estariam relacionados a duas modalidades de contingência entre a ação e suas conseqüências. Mas deve-se ter em conta que os dois fatores constituem duas dimensões separadas, independentes, e não pólos extremos de uma única dimensão, o que quer dizer que é possível encontrar mães que tanto utilizam intensivamente as duas formas de controle como se abstêm de utilizar ambas as formas numa clara posição de laisser faire. Essas duas dimensões ou formas de controle podem ser comparadas aos processos de indução e de sensibilização propostos por Aronfreed (1976) e serviriam, também, para entender estruturas mais globais de interação pais-crianças, como as formuladas por Baumrind (1971). Neste sentido, acredita-se que o uso intensivo das duas formas de controle, interno e externo, corresponderia ao estilo diretivo, a ausência de controle corresponderia ao estilo permissivo e o alto uso do controle externo e baixo do controle interno ao estilo autoritário.

Adotando-se essa nomenclatura e fazendo-se uma comparação entre os resultados aqui encontrados e os encontrados por Baumrind (1971), observa-se que o efeito do controle dos pais tidos como diretivos foi contrário aos resultados encontrados pela autora, uma vez que as crianças deste estudo apresentaram escores baixos de julgamento moral. Já os resultados acerca da influência dos pais tidos como permissivos e dos autoritários aproximaram-se mais dos encontrados por Baumrind.

O fato dos dois tipos de controle observados no presente estudo não constituírem uma única dimensão bipolar, mas dimensões independentes, permite uma análise destes em duas perspectivas distintas: aquela da pressão, ou da freqüência do controle exercido pelos pais, e aquela do conteúdo das técnicas (Hoffman, 1970, 1983). No que concerne ao aspecto da pressão, pode-se distinguir duas situações: a condição "liberal" (nível baixo nos dois controles) e a condição "restritiva" (níveis elevados nos dois controles). Observa-se que as crianças na condição "liberal" obtiveram resultados significativamente superiores aqueles das crianças na condição "restritiva", tanto em relação à agressão como em relação ao roubo. Estes resultados confirmam a idéia de Piaget (1932), segundo a qual a autonomia deixada pelos pais às crianças favoreceria o desenvolvimento moral. É importante constatar que a diferença entre as duas condições é significativa para os dois tipos de ação, o roubo e a agressão.

Em relação ao aspecto do conteúdo dos controles, podese também distinguir entre um estilo puramente indutivo (alto nível de controle interno e baixo nível de controle externo) e um estilo puramente externo (baixo nível de controle interno e alto nível de controle externo). Os resultados mostram que o estilo indutivo é significativamente mais eficaz que o estilo externo, nas histórias em que a ação é o roubo. No caso da agressão, a diferença, se bem que esteja na direção esperada, não atinge o nível de significância. Esta parte dos resultados confirma as hipóteses de Aronfreed (1968), Bandura (1977) e Hoffmam (1970), para quem as crianças aprenderiam dos pais não somente normas precisas, mas também princípios que lhes permitiriam deduzir novas normas que as guiassem em situações novas.

A este propósito, é pertinente observar que o efeito mais marcante da indução aparece nas respostas às histórias sobre o roubo. De fato, as histórias sobre o roubo apresentam situações menos familiares para as crianças do que as histórias sobre agressão, o que exigiria um julgamento mais racional da criança. É possível, então, que as crianças forçadas a pensar, utilizem o que elas aprenderam, seja diretamente dos pais indutivos, seja a partir das experiências com os colegas, facilitadas pelas atitudes liberais dos pais. Mas, é também possível que esses resultados sejam devido a uma menor compreensão das histórias sobre o roubo.

\section{$2^{\circ}$ Estudo, Confirmatório, sobre a Relação entre o Controle Materno e o Julgamento Moral}

Os resultados da primeira pesquisa foram bastante encorajadores, pois tanto os concernentes à existência de dois tipos fundamentais de controle materno como os referentes às relações destes dois tipos de controle materno com o desenvolvimento do julgamento moral correspondem às expectativas levantadas. Apesar disso, o estudo mostrou certas limitações. Primeiramente, por se tratar da uma primeira pesquisa exploratória, tinha-se utilizado uma amostra relativamente pequena, embora satisfatória para as análises estatísticas empregadas. Surgiu, assim, o interesse de efetuar um estudo maior, a fim de replicar esses resultados. 
Mas um segundo aspecto, este mais teórico, sugeria não só repetir o primeiro estudo, como também aprofundá-lo. De fato, os resultados do primeiro estudo levantaram a possibilidade da compreensão ter influenciado no julgamento das histórias de agressão e roubo. Assim, tornou-se necessário controlar essa variável no segundo estudo. Decidiu-se, portanto, não só facilitar a compreensão das histórias utilizando ilustrações de fácil visualização para crianças, mas também controlar o grau de dificuldade das histórias, variando sistematicamente o grau das conseqüências e o tipo de intenções.

Um outro aspecto teórico concernente às técnicas de controle materno indicava também a necessidade de reformular o método empregado na primeira pesquisa. Para que os dois fatores obtidos no primeiro estudo, controles externo e interno, pudessem ser interpretados na perspectiva de Aronfreed (1976), desejou-se verificar se a técnica da "retirada de afeto" - não analisada no primeiro estudo integrar-se-ia ao eixo das técnicas de controle externo, como sugerido por este autor, quando a caracteriza como desaprovação ou ameaça de rejeição. Ao aumentar o número de técnicas, decidiu-se eliminar algumas atividades que, segundo as mães, não constituíam objeto de controle freqüente.

Em relação ao segundo estudo, foram levantadas as seguintes hipóteses:

1) No que concerne às diversas técnicas maternas de controle, espera-se que elas se agrupem nos dois fatores obtidos na primeira pesquisa: o controle externo e o interno, fatores interpretados como correspondendo a dois modelos de relação de contingência entre as ações e suas conseqüências, modelos que são transmitidos pelos pais aos filhos ou que são experimentados pelas crianças a partir de uma certa autonomia dada pelos pais;

2) Espera-se, também, que o controle externo tenha um efeito negativo sobre o desenvolvimento moral das crianças, enquanto que o controle interno tenha um efeito positivo;

3) Espera-se que, nos dilemas em que se contrastem a) um personagem de intenção hostil a um personagem altruísta e b) um personagem de intenção hostil a um personagem sem intenção, seja mais fácil indicar corretamente qual o personagem mais "ruim" do que nos dilemas em que se contrasta c) um personagem com intenção altruísta a um personagem sem intenção.

\section{Método}

Decidiu-se investigar, mais uma vez, numa situação natural, a relação existente entre a forma como a mãe diz controlar o comportamento da criança e o nível de desenvolvimento do julgamento moral desta. Na medida em que se desejava uma amostra maior, escolheu-se um escola de maior porte da rede pública de João Pessoa e convidaram-se as mães das crianças que cursavam o primário a participar do estudo.

\section{Participantes}

Neste segundo estudo, foram observadas 222 crianças e suas respectivas mães. Como no estudo anterior, as mães tinham, em sua maioria, o primário incompleto e eram empregadas domésticas. As crianças encontravam-se nas idades de 5 anos (18 meninos e 19 meninas), 6 anos (19 meninos e 20 meninas), 7 anos ( 16 meninos e 19 meninas), 8 anos (18 meninos e 19 meninas), 9 anos (20 meninos e 20 meninas) e 10 anos (19 meninos e 15 meninas). Todos estas crianças cursavam as séries correspondentes às suas idades.

\section{Instrumentos}

Foram utilizados dois instrumentos: o Instrumento de Julgamento Moral e o Instrumento de Técnicas de Controle. Para o primeiro instrumento, foram elaborados 12 pares de histórias, semelhantes aos da primeira pesquisa, nos quais, além dos dois tipos de conteúdo já utilizados roubo e agressão -, foram manipuladas as intenções, considerando-se três formas de comparação ou contraste de intenções (sem intenção versus intenção hostil; intenção altruísta versus intenção hostil; e sem intenção versus intenção altruísta) e as conseqüências das ações (seis pares com conseqüências iguais e seis com conseqüências diferentes). A fim de facilitar a compreensão das crianças acerca das histórias, estas eram acompanhadas de ilustrações. Para cada uma, havia uma cena relativa à intenção ou à falta de intenção do protagonista de executar uma ação, uma cena sobre a ação do protagonista e uma cena mostrando as conseqüências da ação. Cada história era acompanhada de questões para avaliar o julgamento moral e a compreensão das crianças.

Exemplo: História sobre agressão; contraste sem intenção versus intenção hostil; conseqüências diferentes:

Gabriel tinha consertado um caminhão de madeira. Sem ver, ele deixou uma ponta de prego aparecendo. Um dia, quando ele brincava com o caminhão, na companhia de um amigo, este se feriu seriamente.

Um dia, Pedro decidiu fazer mal a um amigo. Para isto, ele colocou um prego no sapato do menino. Quando o menino se calçou, ele viu rápido o prego e só se furou um pouquinho.

O índice de julgamento moral era obtido com base nas questões: a) Entre Gabriel e Pedro, existe um que seja "mais ruim" do que o outro? b) Quem?. As respostas corretas foram avaliadas com 1 ponto e as erradas com 0 ponto. 


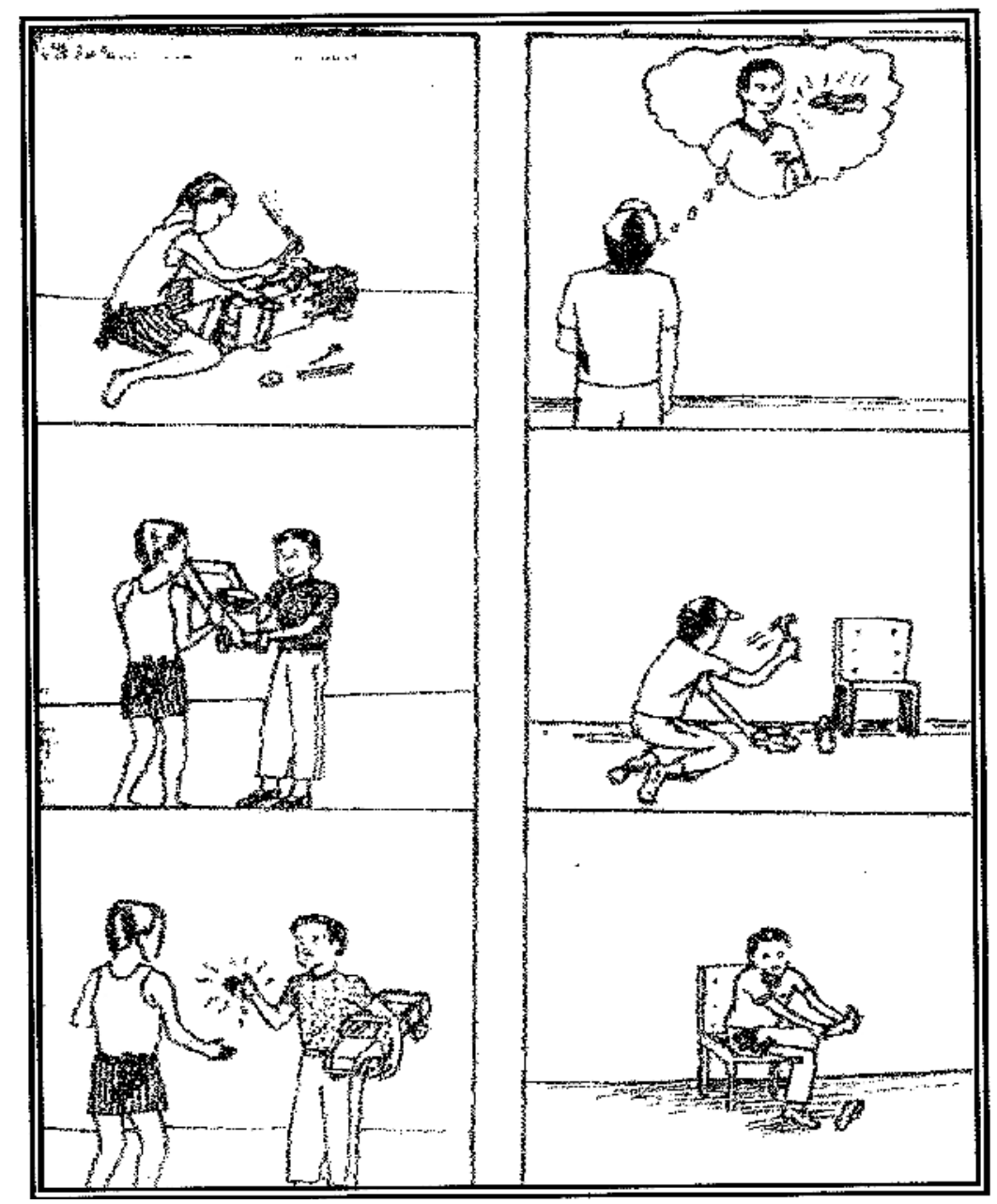

Figura 1. Exemplo das histórias elaboradas para avaliar o índice de julgamento moral.

Já o Instrumento de Técnicas de Controle era semelhante ao da pesquisa anterior, porém com algumas modificações. No que diz respeito ao número de técnicas, estas passaram de 4 para 5 com a introdução da técnica "retirada de afeto". Assim, as técnicas estudadas foram: Punição Real, Recompensa, Punição Sobrenatural, Explicação e Retirada de Afeto. Em relação aos comportamentos, foram suprimidos os relativos a comer, sair na rua sem consentimento, dizer palavrões e brincar com objetos valiosos, considerando-se que estas atividades, segundo as informações dadas pelas mães da primeira pesquisa, não constituíam objeto de controle freqüente. Ficaram, portanto, nove comportamentos e cinco técnicas de controle, o que resultou em 45 itens. Como no estudo anterior, as mães deveriam indicar, para cada técnica, em uma escala de 5 pontos - o 5 correspondendo a Sempre e o 1 a Nunca -, a freqüência com que a utilizavam.

\section{Procedimento}

Semelhante ao da primeira pesquisa, porém as entrevistas sobre o julgamento moral foram realizadas em duas sessões, em lugar de uma. Após a leitura de cada história, mostravase, nos desenhos, os principais episódios, investigando a compreensão da criança. Caso necessário, repetia-se a história o quanto fosse preciso.

\section{Resultados}

Seguindo o mesmo procedimento do estudo anterior, analisar-se-á, inicialmente, as diversas técnicas maternas de controle do comportamento, a fim de ver se essas técnicas se agrupam em torno dos dois eixos encontrados no primeiro estudo. Em um segundo momento, serão analisadas as relações existentes entre as técnicas usadas pelas mães e o julgamento moral das crianças.

\section{Técnicas de Controle: Seus Eixos de Organização}

Para verificar a existência dos dois eixos, externo e interno, empregou-se, como na primeira pesquisa, a Análise pelo Método dos Componentes Principais, mas utilizou-se a rotação oblíqua, porque análises preliminares mostraram que os dois 
Tabela 3.

Índices de Saturação dos dois Fatores Principais por cada Item do Instrumento de Técnicas de Controle Materno

\begin{tabular}{|c|c|c|c|}
\hline Técnicas & Comportamentos & Fator I & Fator II \\
\hline \multirow{9}{*}{ Punição real } & Fazer os deveres da escola & 0,58 & \\
\hline & Agressão física & 0,48 & \\
\hline & Pegar as coisas dos outros & 0,59 & \\
\hline & Agressão verbal & 0,53 & \\
\hline & Se lavar & 0,69 & \\
\hline & Brincar com objetos perigosos & 0,52 & \\
\hline & Mentir & 0,55 & \\
\hline & Jogos sexuais & 0,64 & \\
\hline & Ir dormir & 0,81 & \\
\hline \multirow{9}{*}{ Recompensa } & Fazer os deveres da escola & 0,42 & \\
\hline & Agressão física & 0,63 & \\
\hline & Pegar as coisas dos outros & 0,48 & \\
\hline & Agressão verbal & 0,61 & \\
\hline & Se lavar & 0,56 & \\
\hline & Brincar com objetos perigosos & 0,58 & \\
\hline & Mentir & 0,61 & \\
\hline & Jogos sexuais & 0,60 & \\
\hline & Ir dormir & 0,68 & \\
\hline \multirow{9}{*}{ Punição sobrenatural } & Fazer os deveres da escola & 0,66 & \multirow{6}{*}{0,36} \\
\hline & Agressão física & 0,47 & \\
\hline & Pegar as coisas dos outros & 0,32 & \\
\hline & Agressão verbal & 0,51 & \\
\hline & Se lavar & 0,66 & \\
\hline & Brincar com objetos perigosos & 0,66 & \\
\hline & Mentir & 0,42 & 0,40 \\
\hline & Jogos sexuais & 0,55 & \\
\hline & Ir dormir & 0,77 & \\
\hline \multirow{9}{*}{ Explicação } & Fazer os deveres da escola & \multirow{9}{*}{0,49} & 0,38 \\
\hline & Agressão física & & 0,40 \\
\hline & Pegar as coisas dos outros & & 0,68 \\
\hline & Agressão verbal & & 0,70 \\
\hline & Se lavar & & 0,43 \\
\hline & Brincar com objetos perigosos & & 0,68 \\
\hline & Mentir & & 0,73 \\
\hline & $\begin{array}{l}\text { Jogos sexuais } \\
\text { Ir dormir }\end{array}$ & & - \\
\hline & I1 conimt & & - \\
\hline \multirow{9}{*}{ Retirada de afeto } & Fazer os deveres da escola & \multicolumn{2}{|l|}{0,72} \\
\hline & Agressão física & \multicolumn{2}{|l|}{0,61} \\
\hline & Pegar as coisas dos outros & \multicolumn{2}{|l|}{0,61} \\
\hline & Agressão verbal & \multicolumn{2}{|l|}{0,61} \\
\hline & Se lavar & \multicolumn{2}{|l|}{0,73} \\
\hline & Brincar com objetos perigosos & \multicolumn{2}{|l|}{0,61} \\
\hline & Mentir & \multicolumn{2}{|l|}{0,59} \\
\hline & Jogos sexuais & \multicolumn{2}{|l|}{0,63} \\
\hline & Ir dormir & 0,69 & $-0,46$ \\
\hline \multirow[t]{3}{*}{ Estatísticas } & Eigenvalue & 13,77 & 4,35 \\
\hline & $\%$ de variabilidade explicada & $34 \%$ & $9 \%$ \\
\hline & Coeficiente $\alpha$ de Crombach & 0,81 & 0,79 \\
\hline
\end{tabular}


fatores eram correlacionados (Hartman, 1967). Os resultados, confirmando as hipóteses (Tabela 3), mostram que as 45 questões correspondem a dois fatores principais que explicam em torno de $40 \%$ da variância dos dados. O primeiro fator, que explica $31 \%$ da variância e possui um coeficiente de fidedignidade $\alpha$ de Crombach de 0,81 , é formado por 36 itens: 9 da escala de punição real, 9 da escala de recompensa, 8 da escala de punição sobrenatural (com exceção do item sobre roubo), os 9 itens da escala de retirada de afeto e, surpreendentemente, 1 item da escala de explicação (jogos sexuais). O segundo fator - considerando índices de saturação acima de 0,40 - foi constituído por 6 itens da escala de explicação (os itens sobre roubo, as agressões verbais e físicas, a higiene, os jogos com objetos perigosos, a mentira).

Foram, portanto, encontrados os dois mesmos tipos de controle subjacentes às diversas técnicas, como se tinha obtido na primeira pesquisa. Constatou-se, também, que a técnica de controle "retirada de afeto" fazia parte do controle externo.

\section{Tipo de Controle e Julgamento Moral}

Para verificar a influência dos tipos de controle sobre o julgamento, procedeu-se a uma Análise de Variância dos escores de julgamento moral, utilizando os dois tipos de controle como variáveis independentes e as características dos dilemas morais como medidas repetidas. Esta análise mostra uma interação praticamente significativa entre Ação x Contraste x Controle Externo $(F(9,398)=2,31 ; p=0,057)$, como se pode constatar na Tabela 4.

Com efeito, observa-se, nesta tabela, assim como na primeira pesquisa, o efeito negativo do controle externo sobre o desenvolvimento moral das crianças. Por outro lado, o fato de que a técnica de retirada de afeto integra o controle externo revela seu efeito negativo sobre o desenvolvimento moral e parece confirmar a suposição de Aronfreed (1976) de que haveria conseqüências diferentes na aprendizagem em função de diferenças na maneira em que ocorre a contingência entre a atividade da criança e as formas de controle parental. Observa-se, também, que não há diferenças significativas em função do tipo de ação. Julga-se que isso tenha ocorrido como resultado das modificações metodológicas introduzidas nesta segunda pesquisa.

Já na Tabela 5, constata-se uma tendência à significância para as interações entre Contraste x Controle Externo x Controle Interno $(F(8,398)=1,74 ; p=0,09)$. Embora as médias globais relativas ao julgamento moral nas condições de controle externo baixo e médio não se diferenciem significativamente uma da outra, diferenciamse significativamente da média do controle externo alto e vão na direção das hipóteses e dos resultados obtidos na primeira pesquisa. Isto é, o controle externo alto tem um efeito negativo sobre o julgamento moral das crianças. $\mathrm{E}$ este efeito é significativo quando se analisam as médias de julgamento moral por contraste. Neste caso, observa-se, em cada um dos contrastes (ou das comparações entre intenções), que os escores mais baixos de moralidade encontram-se nas crianças submetidas, ao mesmo tempo, a um alto controle externo e a um baixo controle interno. Observa-se, principalmente nos dois primeiros contrastes - nas duas primeiras comparações -, que os escores mais altos de moralidade encontram-se na confluência de níveis baixos do controles interno e externo.

Por outro lado, verifica-se, como na primeira pesquisa, que o estilo indutivo facilita, significativamente, mais o julgamento moral das crianças do que o estilo externo -

Tabela 4

Médias dos Escores de Julgamento Moral em Função do Tipo de História, Tipo de Contraste e Controle Externo

\begin{tabular}{|c|c|c|c|c|}
\hline \multirow[b]{2}{*}{$\begin{array}{l}\text { Tipo de } \\
\text { história }\end{array}$} & \multirow[b]{2}{*}{$\begin{array}{l}\text { Tipo de } \\
\text { contraste }\end{array}$} & \multicolumn{3}{|c|}{ Controle Externo } \\
\hline & & Baixo & Médio & Alto \\
\hline Agressão & $\begin{array}{l}1^{\circ} \text { contraste } \\
2^{\circ} \text { contraste } \\
3^{\circ} \text { contraste }\end{array}$ & $\begin{array}{l}5,8 \mathrm{ab} \\
5,3 \mathrm{bcd} \\
4,5 \mathrm{fg}\end{array}$ & $\begin{array}{l}5,8 \mathrm{abc} \\
5,9 \mathrm{ab} \\
4,1 \mathrm{~g}\end{array}$ & $\begin{array}{l}5,2 \mathrm{cde} \\
5,0 \mathrm{def} \\
3,0 \mathrm{~h}\end{array}$ \\
\hline Roubo & $\begin{array}{l}1^{\circ} \text { contraste } \\
2^{o} \text { contraste } \\
3^{\circ} \text { contraste }\end{array}$ & $\begin{array}{l}6,1 \mathrm{a} \\
6,1 \mathrm{a} \\
4,5 \mathrm{fg}\end{array}$ & $\begin{array}{l}6,2 \mathrm{a} \\
5,7 \mathrm{abc} \\
4,2 \mathrm{~g}\end{array}$ & $\begin{array}{l}4,7 \text { efg } \\
4,9 \text { def } \\
3,1 \mathrm{~h}\end{array}$ \\
\hline Total con & & $5,4_{\mathrm{A}}$ & $5,3_{\mathrm{A}}$ & $4,3_{\text {в }}$ \\
\hline
\end{tabular}


controle puramente externo -, salvo no segundo contraste. Porém, diferentemente da primeira pesquisa, observa-se que as crianças submetidas concomitantemente a altos controles externo e interno - estilo restritivo - apresentam resultados semelhantes aos do estilo liberal e mais elevados do que os submetidos ao estilo externo. o efeito negativo do controle externo sobre o desenvolvimento do julgamento moral das crianças. $\mathrm{O}$ fato de que a técnica de retirada de afeto também aparece no controle externo, controle que continua a mostrar um efeito negativo sobre o julgamento moral, parece confirmar a primeira interpretação em termos de diferentes sistemas de

Tabela 5

Médias dos Escores de Julgamento Moral em Função dos Contrastes de Intenção e dos Fatores de Controle Externo e Interno

\begin{tabular}{ccccc}
\hline $\begin{array}{c}\text { Contraste de } \\
\text { intenções }\end{array}$ & $\begin{array}{c}\text { Controle } \\
\text { interno }\end{array}$ & Baixo & Médio & Alto \\
\hline $\begin{array}{c}1^{\circ} \text { Contraste } \\
\text { sem intenção }\end{array}$ & baixo & $6,8 \mathrm{a}$ & $6,1 \mathrm{ab}$ & $3,7 \mathrm{c}$ \\
$X$ & médio & $5,5 \mathrm{ab}$ & $6,0 \mathrm{ab}$ & $4,9 \mathrm{bc}$ \\
intenção hostil & alto & $5,5 \mathrm{~b}$ & $6,2 \mathrm{ab}$ \\
$2^{\circ}$ Contraste & & & \\
intenção altruísta & baixo & $5,7 \mathrm{a}$ & $5,8 \mathrm{ab}$ & $4,2 \mathrm{c}$ \\
$X$ & médio & $5,4 \mathrm{abc}$ & $5,6 \mathrm{ab}$ & $4,8 \mathrm{bc}$ \\
intenção hostil & alto & & & $5,9 \mathrm{ab}$ \\
$3^{\circ}$ Contraste & & $4,7 \mathrm{ab}$ & $4,6 \mathrm{ab}$ & $2,2 \mathrm{c}$ \\
sem intenção & baixo & $4,0 \mathrm{ab}$ & $3,7 \mathrm{ab}$ & $3,5 \mathrm{~b}$ \\
$X$ & médio & $4,8 \mathrm{a}$ & $4,1 \mathrm{ab}$ & $3,5 \mathrm{~b}$ \\
intenção altruísta & alto & $5,4 \mathrm{~A}$ & $5,3 \mathrm{~A}$ & $4,3 \mathrm{~B}$ \\
\hline Total controle externo & & & \\
\hline
\end{tabular}

\section{Discussão}

Os resultados obtidos não reproduzem a diferença significativa que se tinha encontrado anteriormente entre a condição "liberal" (nível baixo nos dois tipos de controle) e a condição "restritiva" (nível elevado nos dois tipos de controle), apesar de que as diferenças estejam no sentido esperado. Esta ausência de significância deve-se aos resultados relativamente bons das crianças de estilo restritivo. Estas últimas obtiveram melhores resultados do que as crianças da primeira pesquisa.

A inclusão da técnica de retirada de afeto no fator de controle externo reaproximou-o da condição chamada de "restritiva" - correspondente ao estilo "diretivo" proposto por Baumrind (1971) -, que favoreceria o desenvolvimento moral? Isto é possível, entretanto deve-se considerar que esta observação é apenas sugestiva, pois foram igualmente introduzidas certas modificações no teste de julgamento moral, o que torna mais difícil de precisar as fontes de diferenças entre as duas pesquisas.

Apesar de pequenas diferenças, a segunda pesquisa confirma claramente os resultados da primeira, mostrando contingência entre a atividade da criança e suas conseqüências, que seriam aprendidas nas diferentes formas de controle (Aronfreed, 1968).

\section{$3^{\circ}$ Estudo, Experimental, Sobre a Validade dos Dois Tipos de Controle e sua Relação com o Desenvolvimento do Julgamento Moral}

Tendo em vista os resultados das duas pesquisas de campo, que demonstraram claramente que as diferentes técnicas de controle investigadas agrupam-se em torno de dois fatores, denominados controle externo e controle interno, considerou-se importante realizar um terceiro estudo a fim de validar o Instrumento de Técnicas de Controle Materno e verificar a relação dos controles validados com o desenvolvimento do julgamento moral.

Sendo assim, foram levantadas as seguintes hipóteses:

1) Sobre a validação do instrumento de técnicas de controle materno:

a) Mães de alto controle externo (ACE) no questionário demonstrarão uma maior freqüência de comportamentos de controle externo, em situação experimental, do que as mães de baixo controle externo (BCE) no questionário.

Psicologia: Reflexão e Crítica, 2003, 16(1), pp. 41-61 
b) Mães de alto controle interno (ACI) no questionário demonstrarão uma maior freqüência de comportamentos de controle interno, em situação experimental, do que as mães de baixo controle interno $(\mathrm{BCI})$ no questionário.

c) Mães que no questionário se revelam com estilo restritivo de controle (alto externo/alto interno) mostrarão, em situação de laboratório, um maior uso de ambos os controles em termos comportamentais do que as mães que se revelam de estilo liberal (baixo externo, baixo interno) no questionário.

2) Sobre a relação entre os tipos de controle materno e o julgamento moral:

a) Maior uso de controle externo pela mãe resultará em menor julgamento moral da criança.

b) Maior uso de controle interno pela mãe resultará em maior julgamento moral.

c) Maior uso de restrição pela mãe resultará em menor julgamento moral da criança.

\section{Método}

\section{Estudos Pilotos}

Antes de proceder ao teste experimental dessas hipóteses, fez-se necessário proceder a dois estudos pilotos, a fim de tornar o mais válido possível o conjunto de processos operacionais próprios da pesquisa experimental.

a) Estudos prévios para determinar os brinquedos atrativos: $\mathrm{O}$ objetivo central do procedimento experimental consistia em criar uma situação de tentação real para as crianças, onde se pudesse observar diretamente a maneira como as mães realmente ${ }^{4}$ controlam o comportamento de seus filhos. Como se supôs que as crianças são mais tentadas a tocar os brinquedos mais atrativos, fez-se necessário estabelecer a priori quais os brinquedos de que as crianças, com as características da amostra a ser estudada, mais gostavam e dos que elas menos gostavam.

Para isto, em um primeiro momento, pediu-se às 72 crianças $^{5}$ - alunas da primeira série do primeiro grau de uma escola pertencente à rede pública de ensino da cidade de João Pessoa, Paraíba - para escolherem dentre um grande conjunto de brinquedos aqueles de sua preferência. Esse procedimento permitiu que fossem escolhidos sete brinquedos para meninos e sete para meninas, sendo que para os meninos foram escolhidos: 1 trem, 1 carro grande

\footnotetext{
${ }^{4}$ É evidente que as mães não se comportarão na situação experimental como o fazem na sua casa. Mas certamente este comportamento estará mais perto do natural que as respostas a um questionário. Deve-se ter em conta também que, como todas as mães estão submetidas à mesma situação, as diferenças entre elas devem se aproximar das que existem na vida real.

${ }^{5}$ Estas 72 crianças constituirão, como será visto mais na frente, a primeira fase da pesquisa experimental, o que garante a validade da escolha.

branco, 1 caminhão a pilhas, 1 bola de futebol, 1 carro pequeno vermelho e 1 tanque. Para as meninas: 1 boneca grande, 1 liqüidificador, 1 boneco, 1 jogo de fazer sorvetes, 1 boneca de barbante, 1 jogo de copos e pires e 1 boneca pequena.

Em um segundo momento, testou-se a ordem de preferência por esses brinquedos com 62 crianças, 47 meninas e 15 meninos, pertencentes a diferentes escolas da rede pública da cidade de João Pessoa, com os mesmos níveis sócio-econômicos e de escolaridade, e da mesma faixa etária das 72 crianças do primeiro estudo. Os resultados indicaram que o brinquedo mais atrativo para os meninos foi o trem e, para as meninas, a boneca. Esses brinquedos foram considerados "proibidos" na situação experimental, devendo a mãe evitar que um desses brinquedos fosse tocado.

b) Estudo piloto para elaborar a folha de observação: Fazia-se necessário, também, elaborar uma folha de observação que permitisse registrar as reações das mães na situação experimental. Uma grade de observação foi elaborada a partir das situações descritas no questionário sobre controle materno utilizado no segundo estudo. A viabilidade desta grade de observação foi testada com 18 díades de mães e filhos. Estes eram alunos da primeira série do primeiro grau de uma escola pública de João Pessoa e estavam igualmente distribuídos nas idades de 7 a 9 anos. Os resultados mostraram que a folha de observação não precisava ser modificada, sendo o tempo de registro estabelecido em cinco minutos.

\section{Estudo Experimental}

O objetivo principal da pesquisa era verificar, através de uma situação de laboratório, se o tipo de controle declarado pela mãe no questionário coincidia com o controle exercido por ela na "realidade". Assim, tentouse criar uma situação experimental que reproduzisse aquela do ambiente natural e que permitisse observar as tentativas da mãe de evitar os comportamentos da criança de pegar nos brinquedos proibidos. A fim de facilitar a validação se fazia também necessário escolher mães que possuíssem escores extremos nas duas escalas de controle. Com estes objetivos em mente, desenvolveu-se o estudo em duas fases:

$1^{a}$ Fase: Com o apoio da direção de uma escola pública de João Pessoa , foi solicitada, através de comunicação escrita, a presença da mãe na escola a fim de participar do estudo. Apresentaram-se 72 mães cujos filhos cursavam a primeira série do primeiro grau e encontravam-se nas idades de 7 anos (9 meninos e 7 meninas), 8 anos (17 meninos e 11 meninas), 9 anos (10 meninos e 11 meninas) e 10 anos (5 meninos e 3 meninas). As mães foram convidadas a responder a um questionário sobre as técnicas de controle 
que utilizavam com seus filhos. Posteriormente, as crianças foram contatadas na sala de aulas e convidadas a responder a um conjunto de dilemas morais.

\section{Instrumento para as mães sobre Técnicas de Controle Materno}

O questionário sobre técnicas de controle materno utilizado neste estudo constou de 25 itens extraídos do questionário da segunda pesquisa, usando-se, para a seleção dos itens, o índice de saturação dos mesmos em relação aos dois fatores ou controles (externo e interno). Os 25 itens foram colocados de maneira aleatória. Cada pergunta continha cinco alternativas de resposta: sempre, muitas vezes, regularmente, poucas vezes e nunca.

A composição formal do questionário foi a seguinte: 8 itens sobre retirada de afeto, 3 itens sobre ameaça de punição real, 5 itens sobre promessa de recompensa, 4 itens sobre punição sobrenatural e 5 itens sobre explicação.

\section{Instrumento de Julgamento Moral}

A entrevista constou de dois pares de dilemas morais com conteúdo agressivo, retirados da segunda pesquisa. Optou-se, nesta pesquisa, pela redução do número de dilemas a fim de não cansar as crianças, pois algumas destas deveriam participar da segunda fase. A escolha dos dilemas com conteúdo agressivo foi motivada pelo fato de, na abordagem construtivista, esse conteúdo ser pouco usado.

$2^{\text {a }}$ Fase: Nesta fase, extraíram-se da amostra total 28 crianças, 14 meninos e 14 meninas, cujas mães foram classificadas pelo Instrumento de Técnicas de Controle como de alto ou baixo controle externo e de alto ou baixo controle interno. Foram consideradas como de alto controle as mães cujos escores situavam-se acima do percentil 66,6 e de baixo controle as mães cujos escores situavam-se abaixo do percentil 33,3. As mães assim selecionadas foram solicitadas, através de comunicação escrita, a se apresentar, junto com seus filhos, no centro de estudos da escola, em dias e horas previamente determinados. Grupos de 4 a 6 mães, com seus filhos, eram transportados da escola até a Clínica Psicológica da Universidade Federal da Paraíba (UFPB), permanecendo na sala de espera até serem chamados. Quando eram, então, conduzidos, por uma das colaboradoras do estudo, à sala especialmente equipada para a observação, eralhes comunicado que tinham de "esperar" por uns minutos para serem atendidos, dizendo-se à mãe o seguinte: "A criança pode brincar com estes brinquedos (assinalando os que estavam em cima da escrivaninha), porém, por favor, a senhora tenha cuidado para que ela não toque neste brinquedo (mostrando o "objeto proibido"), porque pode quebrar-se, estragar-se, e não é nosso". Dadas estas instruções, deixava-se a mãe e a criança a sós, fechando a porta, dando assim início à observação do comportamento da mãe por duas observadoras. Eram, então, anotadas, na folha de observação experimental, as verbalizações, os gestos, atos da mãe para evitar que seu filho tocasse no objeto proibido.

Nesta sala, havia uma escrivaninha, brinquedos, 2 cadeiras e um espelho unilateral. Sobre a escrivaninha, situada num ângulo da sala, foram colocados os brinquedos com os quais as criança podiam entreter-se. Ao lado direito da escrivaninha, havia uma cadeira destinada à mãe, ao lado esquerdo havia outra cadeira para a criança. Esta disposição foi considerada mais adequada para se observar o comportamento da mãe (gestos, expressões não verbais, etc.), através do espelho unilateral que se encontrava às costas da criança. Os brinquedos "proibidos" - trem para os meninos e boneca para as meninas -, considerados os mais atrativos no estudo prévio, foram colocados a uma certa distância da criança, para que ela, ao querer pegá-lo, tivesse que se dirigir expressamente para ele. Transcorridos cinco minutos, uma assistente aparecia, batendo previamente à porta, anunciando que já podiam ser atendidos. Nesse momento, aplicava-se à criança o terceiro par de histórias sobre julgamento moral, justificando, assim, a presença da mãe e da criança na clínica.

\section{Resultados}

Neste último estudo, verificar-se-á, inicialmente, a validade do Instrumento de Técnicas de Controle comparando-se os escores dados a este questionário com os comportamentos observados na situação experimental para, num segundo momento, como foi feito nos dois primeiros estudos, analisar a relação entre as técnicas empregadas pelas mães e o desenvolvimento do julgamento moral dos filhos.

\section{Validação do Instrumento}

Como se pode observar na Tabela 6, as mães - ACE de alto controle externo, avaliado no questionário, utilizam com maior freqüência $(m=1,00)$ comportamentos de controle externo do que as mães - BCE - de baixo controle externo $(m=0,11)$, o que confirma a primeira hipótese sobre a validade do questionário utilizado. No que concerne à segunda hipótese, os resultados mostram que as mães - ACI - de alto controle interno apresentam uma média de comportamentos internos $(m=0,17)$, o que revela apenas uma tendência a se diferenciar significativamente da média $(m=0,0)$ apresentada pelas mães - BCI - de baixo controle interno, o que indica que essa hipótese, embora não confirmada totalmente, também não é invalidada. 
Tabela 6

Médias de Intervenções das Mães Utilizando Técnicas de Controle Externo e Interno em Função dos Níveis Obtidos nas Escalas de Controle Externo e Interno

\begin{tabular}{cllllll}
\hline $\begin{array}{c}\text { Freqüências observadas das } \\
\text { mães usando técnicas: }\end{array}$ & \multicolumn{3}{c}{ Classificação das mães nas escalas de controle: } & $\begin{array}{c}\text { Testes estatísticos } \\
\text { unicaudais }\end{array}$ \\
\hline \multirow{3}{*}{ de controle externo } & Baixo externo & (BCE) & Alto externo & {$[\mathrm{ACE}]$} & & \\
& $m$ & $n ; d p$ & $m$ & $n ; d p$ & $\mathrm{~T}_{20}$ & $p<$ \\
& 0,11 & $(09) ; 0,33$ & 1,00 & $(13) ; 1,15$ & $-2,62$ & 0,01 \\
& Baixo interno & $(\mathrm{BCI})$ & $m$ & {$[\mathrm{ACI}]$} & & \\
de controle interno & $m$ & $n ; d p$ & $m$ & $n ; d p$ & $\mathrm{~T}_{20}$ & $p$ \\
& 0,0 & $(10) ; 0,00$ & 0,17 & $(12) ; 0,39$ & $<-1,35$ & 0,09 \\
\hline
\end{tabular}

Tabela 7

Médias de Intervenções das Mães Utilizando Técnicas de Controle Externo e Interno em Função dos Estilos de Controle Apresentados nas Escalas

\begin{tabular}{|c|c|c|c|c|c|c|}
\hline \multirow{2}{*}{$\begin{array}{l}\text { Freqüências observadas das } \\
\text { mães usando técnicas: }\end{array}$} & \multicolumn{4}{|c|}{ Estilos de controle das mães } & \multicolumn{2}{|c|}{ Testes estatísticos unicaudais } \\
\hline & \multicolumn{2}{|c|}{ Estilo liberal $(n=11)$} & \multicolumn{2}{|c|}{ Restritivo $(n=08)$} & & \\
\hline de controle externo & $\begin{array}{l}m \\
0,00\end{array}$ & $\begin{array}{l}d p \\
0,00\end{array}$ & $\begin{array}{l}m \\
0,25\end{array}$ & $\begin{array}{l}d p \\
0,46\end{array}$ & $\begin{array}{r}\mathrm{T}_{17} \\
-1,81\end{array}$ & $\begin{array}{c}p< \\
0,04\end{array}$ \\
\hline de controle interno & $\begin{array}{l}m \\
0,00\end{array}$ & $\begin{array}{l}d p \\
0,00\end{array}$ & $\begin{array}{l}m \\
0,87\end{array}$ & $\begin{array}{l}d p \\
1,46\end{array}$ & $\begin{array}{r}\mathrm{T}_{17} \\
-2,01\end{array}$ & $\begin{array}{c}p< \\
0,03\end{array}$ \\
\hline
\end{tabular}

Tabela 8

Escores Médios de Julgamento Moral das Crianças em Função dos Niveis de cada Escala de Controle e dos Estilos Obtidos na Combinação de Ambas

\begin{tabular}{|c|c|c|c|c|c|c|c|}
\hline \multicolumn{6}{|c|}{ Classificação das mães nas Escalas de Controle } & \multicolumn{2}{|c|}{ Análises estatísticas } \\
\hline \multicolumn{3}{|c|}{ Baixo controle externo [BCE] } & \multicolumn{3}{|c|}{ Alto controle externo [ACE] } & \multicolumn{2}{|c|}{ Teste " $t$ " } \\
\hline$m$ & $N$ & $d p$ & $m$ & $N$ & $d p$ & $\mathrm{~T}_{20}$ & $p<$ \\
\hline 7,09 & 12 & 1,30 & 6,70 & 10 & 2,75 & $<1$ & n. sig. \\
\hline \multicolumn{3}{|c|}{ Baixo controle interno [BCI] } & \multicolumn{3}{|c|}{ Alto controle interno $[\mathrm{ACI}]$} & \multicolumn{2}{|c|}{ Teste "t" } \\
\hline$m$ & $N$ & $d p$ & $m$ & $N$ & $d p$ & $\mathrm{~T}_{20}$ & $p<$ \\
\hline 6,30 & 10 & 1,84 & 7,41 & 12 & 2,06 & $-1,31$ & 0,10 \\
\hline \multicolumn{3}{|c|}{ Estilo liberal } & \multicolumn{3}{|c|}{ Estilo restritivo } & \multicolumn{2}{|c|}{ Teste " $\mathrm{t}$ " } \\
\hline$m$ & $N$ & $d p$ & $m$ & $N$ & $d p$ & $\mathrm{~T}_{11}$ & $p<$ \\
\hline 6,67 & 06 & 1,21 & 7,28 & 07 & 2,51 & $<1$ & n. sig. \\
\hline
\end{tabular}

Finalmente, quando se comparam os estilos de controle das mães obtidos nas diversas combinações dos dois tipos de controle, pode-se observar que a terceira hipótese é plenamente confirmada. Isto significa que as mães que foram classificadas, a partir dos seus escores no questionário, como utilizadoras do estilo liberal (baixo controle interno e externo) foram significativamente menos utilizadoras, na situação experimental, dos controles interno e externo, do que as mães classificadas como restritivas (alto controle interno e externo), conforme Tabela 7.
Técnicas de Controle Materno e o Julgamento Moral

As hipóteses concernentes à influência dos tipos de controle no desenvolvimento do julgamento moral não foram confirmadas (Tabela 8), entretanto, todos os resultados estão na direção esperada. Assim, ao nível alto de controle externo correspondem resultados mais baixos no julgamento moral do que no nível baixo de controle externo, enquanto que ao nível alto de controle interno correspondem resultados mais elevados de julgamento moral do que no nível baixo de controle interno. Neste 
último resultado, a diferença tende a ser significativa. Já as hipóteses concernentes à relação entre estilos de controle e julgamento moral não foram confirmadas, nem vão na direção esperada. Como se pode observar na Tabela 8, o julgamento moral das crianças cujas mães possuem estilo liberal não se diferencia daquele das crianças cujas mães possuem estilo restritivo.

\section{Discussão}

O conjunto de resultados obtidos através da última pesquisa relatada permite considerar os dois aspectos centrais dos três estudos: tipos de controle materno e julgamento moral.

Mães que se auto avaliaram como utilizadoras de alto controle externo no questionário realmente utilizaram, na situação de laboratório, em maior freqüência este tipo de controle do que mães de baixo controle externo. Também foi observado, na situação de laboratório, o uso freqüente de controle interno declarado pelas mães no questionário. Igualmente, verificou-se que mães categorizadas como de estilo restritivo (alto controle externo e alto controle interno) demonstraram maior uso de alto controle externo e de alto controle interno do que mães de estilo liberal.

Com relação à influência das técnicas de controle materno sobre o julgamento moral da criança, não foram encontrados resultados significativos. A explicação mais adequada para este fato parece ser a seguinte: nas investigações anteriores foram utilizados 12 pares de histórias, enquanto no presente estudo foram aplicados somente três pares de histórias. É possível que estes nove pares possuam maior poder de discriminação e detecção dos fatores envolvidos em cada tipo de controle. Uma outra justificativa poderia ser encontrada no tamanho da amostra. Nos estudos anteriores, participaram mais de 100 crianças, enquanto no presente estudo, o julgamento moral foi avaliado apenas em parte da amostra (28 crianças).

\section{Conclusões}

O primeiro aspecto que será abordado nesta discussão final é constituído pelas técnicas maternas de controle. Discutir-se-á este ponto sob uma dupla perspectiva: estudarse-á primeiro a natureza de diferentes técnicas maternas de controle para, em seguida, estudar os efeitos dos diversos contrastes ou estilos sobre o julgamento moral.

No que concerne à natureza das técnicas de controle, as duas primeiras pesquisas mostraram a existência de dois fatores principais subjacentes às diversas técnicas. Além disto, na terceira pesquisa, em que se busca validar o questionário de técnicas maternas de controle, verifica-se nos resultados, claramente, que o questionário avalia o que pretende avaliar, sobretudo no que diz respeito ao controle externo.
Desde a primeira pesquisa, tem-se conceituado a natureza destes dois fatores principais em função do modelo de contingência entre o ato proibido e as conseqüências que a transgressão acarreta. No primeiro fator, é um modelo externo de contingência que é utilizado pelos pais: as conseqüências para a criança, tanto positivas como negativas, seriam produzidas não pelo ato, em si, da transgressão, mas pela intervenção de um agente exterior real (no sentido físico) ou espiritual. Ao contrário, no segundo fator, o acento é colocado sobre as conseqüências negativas intrínsecas ao ato de transgressão.

Esta interpretação teórica em função do modelo de contingência entre $O$ ato e suas conseqüências, utilizado pelos pais, parece confirmada, na segunda pesquisa, pelo fato de que a técnica de retirada de afeto faz claramente parte do controle externo. Em geral, esta técnica é identificada como técnica indutiva, sob o termo de técnicas psicológicas (Allinsmith \& Greening,1955; Aronfreed, 1961), ou como uma técnica intermediária entre as técnicas indutivas e as técnicas coercitivas (Hoffman, 1970, 1983).

Mas se pode igualmente pensar que o elo comum seria constituído pelo fato de que todas essas técnicas orientam a criança para si mesma e para as conseqüências negativas que poderiam lhe acontecer em caso de transgressão. É necessário, porém, lembrar que, nas duas pesquisas, as questões sobre a técnica explicativa faziam referência, simultaneamente, às conseqüências negativas para o sujeito e para outras pessoas. E em certos comportamentos, como estudar, se lavar, ir dormir, etc., a totalidade das conseqüências negativas sugeridas era centrada sobre a própria criança.

Por outro lado, é interessante distinguir no interior das técnicas explicativas, conforme Hoffman $(1970,1983)$, as técnicas indutivas orientadas para as conseqüências sociais dos atos das técnicas racionais que explicariam as conseqüências para o próprio sujeito. Segundo esse autor, estas diferentes formas de indução afetariam diferentemente a concepção moral das crianças. As crianças e os adolescentes cujos pais utilizam freqüentemente as técnicas indutivas teriam uma concepção moral humanitária em oposição à moral convencional das crianças cujos pais ressaltam tanto os aspectos normativos como as conseqüências materiais das transgressões. As crianças submetidas a uma coerção externa permaneceriam em uma moral objetiva.

Em conclusão, julga-se, pois, que a concepção de dois controles principais em função do modelo de contingência entre $\mathrm{o}$ ato e suas conseqüências parece se acomodar bem, tanto aos dados das pesquisas aqui apresentadas como aqueles de outras pesquisas. Pode-se, agora, passar à discussão dos efeitos das duas técnicas principais sobre o julgamento moral. 
A partir da interpretação teórica que se tem dado a cada um dos dois controles principais (fatores), pode-se melhor compreender através de quais processos se efetuam as suas influências sobre o julgamento moral das crianças. Assim, o controle externo, fazendo repousar as conseqüências tanto negativas como positivas para a criança sobre os agentes sociais, reforça a dependência externa desta, dificultando o processo de socialização (Hoffman, 1970, 1983; Maccoby \& Martin, 1983). As noções do bem e do mal ficariam, assim, ligadas ao querer das autoridades. A criança não atingiria uma moralidade heterônoma subjetiva, porque o modelo de contingência externa não conduz a criança à descoberta de sua responsabilidade frente às conseqüências negativas, que derivam de sua própria ação. Esta dependência constitui uma característica essencial da moralidade heterônoma descrita por Piaget (1932).

Um outro aspecto negativo das conseqüências do controle externo para as crianças, quando a punição física é utilizada, diz respeito ao surgimento de comportamentos agressivos na criança e às dificuldades desta de processar adequadamente informações sociais (Weiss, Dodge, Bates \& Pettit, 1992). Também sobre o efeito negativo da punição, Crano e Mendoza (1987) verificaram que as mães punitivas dificultam as relações sociais de seus filhos.

Ao contrário, as técnicas explicativas - racionais ou indutivas -, ao dirigir a atenção da criança sobre as conseqüências futuras da sua ação, sobre o meio e sobre si mesma, em domínios que não são apenas de satisfação ou de prazeres imediatos, facilitariam tanto os processos de descentração da criança como a aquisição do sentimento de responsabilidade em relação a seus atos. Neste sentido, considera-se, numa perspectiva diferente da de Piaget, que as relações hierarquizadas não são apenas reforçadoras da moral heterônoma - etapa necessária na primeira infância -, mas que também podem beneficiar a moral autônoma, uma vez que a relação desigual pode orientar a criança para um sistema de comunicação que lhe permita uma melhor aprendizagem de seu meio. É interessante lembrar, a este propósito, a distinção proposta por Baumrind $(1971,1991)$ entre estilo parental autoritário e estilo diretivo. Neste último, os pais, sem nada negar sobre sua posição hierarquizada, orientam a criança para objetivos precisos e para um melhor aprendizado das conseqüências de suas ações sobre o meio.

Mas é evidente que esta aprendizagem pode se produzir pela própria experiência da criança com seus colegas, quando ela se sente livre para experimentar e adotar suas próprias reações. Isto explicaria os resultados elevados obtidos, nas duas primeiras pesquisas, pelas crianças submetidas à condição denominada liberal. Este último resultado vai na mesma direção das idéias de Piaget
(1932), para quem a criança se desenvolveria moralmente à medida que seus pais e outras figuras de autoridade diminuíssem suas influências coercitivas. Porém, antes de adotar este ponto de vista, é importante investigar se em vez de ser a condição liberal que influencia o nível moral da criança, como se supõe aqui, é a criança que influencia a mãe, pelo fato de não apresentar necessidade de um maior controle materno. A este respeito, Kochanska (1993) verificou que alguns aspectos da criança, como a vulnerabilidade para a ansiedade, influenciam na escolha que os pais fazem de estratégias disciplinares.

Além disso, como indicado no início do trabalho, os diversos mecanismos de socialização que estão em jogo no desenvolvimento da moralidade devem ser colocados num contexto mais completo que, além das relações interpessoais, incluam tanto os fatores sócio-econômicos como o conjunto de valores que regem uma determinada sociedade. Sendo assim, pode-se pensar que a preferência por um ou outro tipo de técnica de controle parental estaria ligada ao maior ou menor grau de adesão dos pais a determinados valores sociais. De fato, quando o uso das técnicas de controle interno ou indutivo refere-se à prevenção de conseqüências tanto pessoais como coletivas de uma ação, pode-se pensar que elas estariam ligadas à valorização do desenvolvimento pessoal e coletivo. Por outro lado, ao centrar-se nas conseqüências externas e materiais da desobediência a uma norma, o uso das técnicas de controle externo estaria ligado à valorização do conformismo e dos valores materiais.

É neste sentido que se pode repensar o papel das técnicas de controle parental na atual crise de valores pela qual passa a sociedade brasileira. O uso majoritário, na prática, de técnicas de controle externo, observado no terceiro estudo, estaria reforçando valores materialistas e conformistas observáveis em nossa sociedade. Musitu e García (2001), utilizando a teoria de valores de Schwartz (Schwartz, 1994; Schwartz \& Bilsky, 1987, 1990) observaram, na Espanha, que filhos de pais indutivos aderiam mais aos valores do Universalismo/Benevolência, enquanto que os filhos de pais coercitivos aderiam mais a valores materialistas.

Por outro lado, Inglehart $(1977,1991,1994)$ tem mostrado a estreita relação entre o desenvolvimento social e econômico de uma sociedade e os valores desta. Numa perspectiva psicossociológica, Pereira, Lima e Camino (2001) têm mostrado, em estudantes universitários, que a adesão aos valores pós-materialistas está relacionada com atitudes positivas frente à democracia, enquanto que a adesão a valores religiosos conformistas estaria relacionada a atitudes negativas. Desta forma, coloca-se como um objetivo a ser alcançado o estudo, no Brasil, da relação entre técnicas de socialização e valores sociais. 


\section{Referências}

Allinsmith, W. \& Greening, T. C. (1955). Guilt over anger as predicted from parental discipline: A study of superego development. American Psychologist, 10,320 .

Apel, K-O. (1992). Estudos de moral moderna. Petrópolis, RJ: Vozes.

Aronfreed, J. (1961). The nature, variety and social patterning of internationalized response to transgression. Journal of Abnormal and Social Psychology, 63, 223240.

Aronfreed, J. (1968). Conduct and conscience: The socialization of internalized control over behavior. New York: Academic Press.

Aronfreed, J. (1976). Moral development from the standpoint of a general psychological theory. Em T. Lickona (Org.), Moral development and behavior: Theory, research and social issues (pp. 54-69). New York: Holt, Rinehart and Winston.

Bandura, A. (1977). Social learning theory. New Jersey: Prentice-Hall.

Baumrind, D. (1968). Authoritarian vs. authoritative parental control. Adolescence, 3, 255-272.

Baumrind, D. (1971). Current patterns of parental authority. Developmental Psychology Monograph, 4, 1-103.

Baumrind, D. (1991). The influence of parenting style on adolescent competence and substance use. Journal of Early Adolescence, 11, 56-95.

Baumrind, D. (1996). The discipline controversy revisited. Family Relations, 45, 405-414.

Brown, R. (1965). Social Psychology. New York: Free Press.

Camino, C., Batista, L., Reis, R., Rique, J., Luna, V. \& Cavalcanti, M. G. (1994). A transmissão de valores morais em personagens de TV. Psicologia: Reflexão e Crítica, 7, 29-46.

Camino, C. \& Cavalcanti, M. G. (1998). Valores morais transmitidos por telenovelas brasileiras: Vale Tudo, Tieta, Salvador da Pátria. Em M. L. T. Nunes (Org.), Moral \& TV (pp. 90-148). Porto Alegre: Evangraf.

Camino, C., Cavalcanti, M. G. \& Rique, J. (1992). Empathy and morality [Resumo]. Resumos de comunicações cientificas, XXV International Congress of Psychology (p. 226). Bruxelles, Belgique.

Camino C., Camino, L. \& Leyens J-P. (1996). Julgamento moral, emoção e empatia. Em Z. A. Trindade \& C. Camino (Orgs.), Cognição social e juízo moral (pp. 109-135). Rio de Janeiro: ANPEPP.

Camino, L. (1996). A socialização política: Uma análise em termos de participação social. Em L. Camino \& P. R. M. Menandro (Orgs.), A sociedade na perspectiva da psicologia: Questões teóricas e metodológicas (pp. 1436). Rio de Janeiro: ANPEPP.

Camino, L., Da Silva, P., Machado, A. \& Pereira, C. (2001). A face oculta do racismo no Brasil: Uma análise psicossociológica. Revista Psicologia Política, 1, 13-36.

Chapman, M. (1979). Listening to reason: Children's attentiveness and parental discipline. Merrill-Palmer Quarterly, 25, 251-263.

Crano, W. D. \& Mendoza, J. L. (1987). Maternal factors that influence children's positive behavior: Demonstration of a structural equation analysis of selected data from the Berkeley Growth study. Child Development, 58, 38-48.

Darling, N. \& Steinberg, L. (1993). Parenting style as context: An integrative model. Psychological Bulletin, 113, 487-496.

Habermas, J. (1973/1978). Raison et légitimité. Problèmes de légitimation dans le capitalisme avancé. Paris: Éditions Payot.

Hartman, H. (1967). Modern factor analysis. Chicago: University of Chicago Press.

Hoffman, M. L. (1960). Power assertion by the parent and its impact on the child. Child Development, 31, 129-143.

Hoffman, M. L. (1963a). Child-rearing practices and moral development: Generalizations from empirical research. Child Development, 34, 295318.

Hoffman, M. L. (1963b). Parent discipline and the child's consideration for others. Child Development, 34, 573-588.

Hoffman, M. L. (1970). Moral development. Em P. H. Mussen (Org.), Handbook of child psychology: Infancy and developmental psychobiology (Vol. 2, pp. 261-354). New York: Wiley.
Hoffman, M. L. (1975). Moral internalization, parental power, and the nature of parent-child interaction. Developmental Psychology, 11, 228-239.

Hoffman, M. L. (1983). Affective and cognitive processes in moral internalization: An information processing approach. Em E. T. Higgins, D. Rufly \& W. Hartup (Orgs.), Social cognition and social development: A socio-cultural perspective (pp. 236-274). New York: Cambridge University Press.

Hoffman, M. L. (1994). Discipline and internalization. Developmental Psychology, 30, 26-28.

Hoffman, M. L. \& Saltzstein, H. (1967). Parent discipline and the child's moral development. Journal of Personality and Social Psychology, 5, 45-57.

Inglehart, R. (1977). The silent revolution. Princenton: Princenton University Press.

Inglehart, R. (1991). El cambio cultural en las sociedades industriales avanzadas. Madrid: Siglo XXI de España Editores.

Inglehart, R. (1994). Modernización y pós-modernización: La cambiante relación entre el desarrollo económico, cambio cultural y político. Em J. D. Nicolás \& R. Inglehart (Orgs.), Tendencias mundiales de cambio en los valores sociales y politicos (pp. 63-107). Madrid: Fundesco.

Jones, E. E. \& Gerard, H. B. (1967). Foundations of social psychology. New York: Wiley \& Sons.

Kaye, K. (1982). The mental and social life of babies. Brigthon: Harvester.

Kochanska, G. (1993). Toward a synthesis of parental socialization and child temperament in early development of conscience. Child Development, 64, 325-347.

Kohlberg, L. (1976). Moral stages and moralization: The cognitive-developmental approach. Em T. Lickona (Org.), Moral development and behavior: Theory, research and social issues (pp. 31-53). New York: Holt, Rinehart and Winston.

Kohlberg, L. (1984). Essays on moral development: The psychology of moral development (Vol. 2). New York: Harper \& Row.

Maccoby, E. (1994). The role of parents in the socialization of children: An historical overview. Em R. D. Parke, P. A. Ornstein, J. J. Rieser \& C. Zahn-Waxler (Orgs.), A century of developmental psychology (pp. 589-615). Washington, DC: American Psychological Association.

Maccoby, E. \& Martin, J. (1983). Socialization in the context of the family: Parent-child interaction. Em P. H. Mussen (Org.), Handbook of child psychology: Socialization, personality, and social development (Vol. 4, pp. 1-101). New York: Wiley.

Musitu, G. \& García, F. (2001). Escala de socialización parental en la adolescencia. Madrid: TEA.

Parke, R. D. (1977). Punishment in children: Effects, side effects and alternative strategies. Em H. L. Hom Jr. \& P. Robinson (Orgs.), Psychological processes in early education (pp. 71-97). San Diego: Academic Press.

Pereira, C. R., Lima, M. E. \& Camino, L. (2001). Sistemas de valores e atitudes democráticas de estudantes universitários de João Pessoa. Psicologia: Reflexão e Crítica, 14, 177-190.

Piaget, J. (1932). Le jugement moral chez l'enfant. Paris: Alcan.

Piaget, J. (1964). Six études de Psychologie. Genève: Gonthier.

Piaget, J. (1975). L'equilibration des structures cognitives. Paris: PUF.

Rawls, J. (1971/1981). Uma teoria da justiça. Brasília: Editora Universidade de Brasília.

Schaffer, H. R. (1984). Parental control techniques in the context of socialization theory. Em W. Doise \& A. Palmonari (Orgs.), Social interaction in individual development (pp. 65-77). Cambridge: Cambridge University Press.

Schwartz, S. H. (1994). Are there universal aspects in the structure and contents of human values? Journal of Social Issues, 50, 19-45.

Schwartz, S. H. \& Bilsky, W. (1987). Toward a universal psychological structure of human values. Journal of Personality and Social Psychology, 53, $550-562$.

Schwartz, S. H. \& Bilsky, W. (1990). Toward a theory of the universal content and structure of values: Extensions and cross-cultural repliecations. Journal of Personality and Social Psychology, 58, 878-891.

Secord, P. F. \& Backman, C. W. (1964). Social Psychology. New York: McGrawHill. 
Tajfel, H. (1981). Human groups and social categories. Cambridge: Cambridge University Press.

Vasquez, S. (1969/1983). Ética. Rio de Janeiro: Civilização Brasileira.

Walker, L. J. (1999). The family context for moral development. Journal of Moral Education, 28, 261-264.

Weiss, B., Dodge, K. A., Bates, J. E. \& Pettit, G. S. (1992). Some consequences of early harsh discipline: Child aggression and a maladaptive social information processing style. Child Development, 63, 1321-1335.
Zigler, E. \& Child I. L. (1969). Socialization. Em G. Lindzey \& E. Aronson (Orgs.), The bandbook of Social Psychology (Vol. 3, pp. 450-589). Massachusetts: Addison-Wesley.

\section{Sobre os autores}

Cleonice Camino é Professora da Universidade Federal de Pernambuco.

Leoncio Camino é Professor da Universidade Federal da Paraíba.

Raquel Moraes é Mestre em Psicologia pela Universidade Federal de Pernambuco. É Professora da Universidade Estadual da Paraíba. 


\section{Grupo de Pesquisa em Interação Social Desenvolvimento e Psicopatologia - GIDEP -}

O objetivo do GIDEP é produzir conhecimentos para a teoria e prática na área de desenvolvimento e psicopatologia. Em particular, busca-se investigar os fatores socio-emocionais e cognitivos no desenvolvimento normal e atípico dentro do contexto de interações paiscriança, criança-criança, e adolescente-família. O GIDEP está empenhado na qualificação de pesquisadores e profissionais dentro de uma perspectiva interdisciplinar. O GIDEP constituise em um dos Grupos de Pesquisa do CNPq/UFRGS. Sete teses e 39 dissertações foram defendidas ou estão em orientação no Grupo.

Participantes e linhas de pesquisa

Cesar A. Piccinini (PhD pela University of London): Interação pais-bebê/criança; Apego e temperamento infantil; Estratégias educativas parentais.

Tânia M. Sperb (PhD pela University of London): Interação de crianças; Cultura e desenvolvimento; Narrativas, desenvolvimento e psicopatologia.

Rita Sobreira-Lopes ( $\mathrm{PhD}$ pela University of London): O desenvolvimento sócio-afetivo no contexto das relações familiares; relações pais-filhos em momentos de transição; Desenvolvimento da autonomia na família.

Participam ainda do grupo um técnico de audiovisual, 07 Doutorandos, 10 Mestrandos, e 09 Bolsistas de Iniciação Científica.

Cleonice $\boldsymbol{A}$. Bosa ( $\mathrm{PhD}$ pela University of London): interação pais-criança e desenvolvimento atípico; impacto dos transtornos do desenvolvimento na família; autismo.

Infra-estrutura do GIDEP: O Grupo mantém o Laboratório de Observação de Processos Interativos equipado com sofisticados equipamentos de gravação, digitalização e edição de imagens de vídeo, o que possibilita análises sistemáticas das observações gravadas.

Contatos internacionais e convidados pelo Grupo: Artin Goncu (EUA/1993); Annette Watilon (Bélgica/1997); Jan Valsiner (EUA/1995); Jonathan Tudge (EUA/desde 1994); Marc Bigras (Canadá/1999); Palácio Espasa (Suiça/1997); Stuart Millar (Inglaterra/desde 1996).

\section{Endereço:}

GIDEP/CPG Psicologia/UFRGS

Rua Ramiro Barcelos, 2600

90035.003, Porto Alegre, RS

Fone: (51) 33309507 